\title{
Are There High-Tech Industries or Only High-Tech Firms? Evidence From New Technology-Based Firms
}

\author{
by \\ John R. Baldwin * \\ and \\ Guy Gellatly** \\ No. 120 \\ 11F0019MPE No. 120 \\ ISSN: 1200-5223 \\ ISBN: 0-660-17666-1
Micro-Economic Analysis Division
24-B R.H. Coats Building
Ottawa, K1A 0T6
Statistics Canada \\ Facsimile Number: (613) 951-5403 \\ * (613) 951-8588 \\ Email: baldjoh@statcan.ca \\ ** (613) 951-3758 \\ Email: gellguy@statcan.ca
}

\section{December 1998}

The ideas in this paper are those of the authors and do not necessarily reflect the opinions of Statistics Canada. 


\section{Table of Contents}

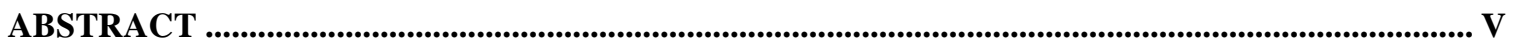

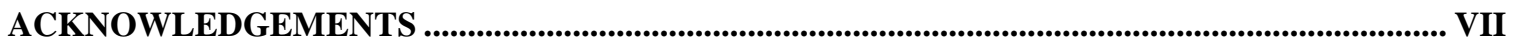

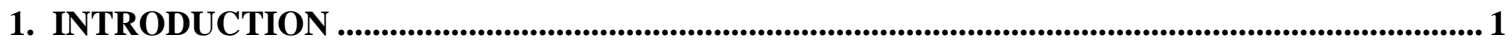

2. EXISTING CLASSIFICATION SCHEMES OF HIGH-TECH OR KNOWLEDGE-BASED

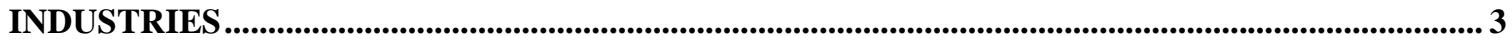

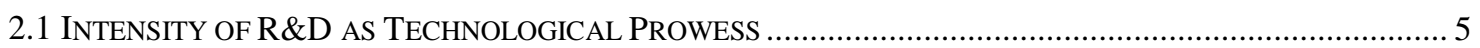

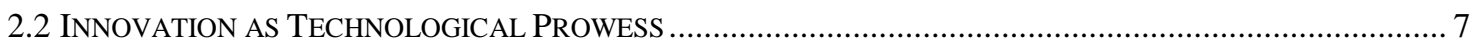

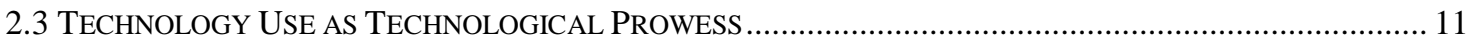

3. A COMPETENCY-BASED APPROACH......................................................................................... 15

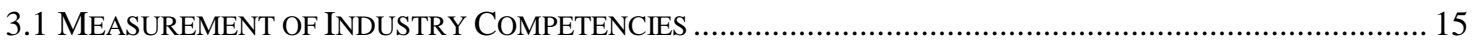

3.2 Data AND Definitions: The SURVEY OF OPERATING AND FinANCING PRACTICES ............................ 16

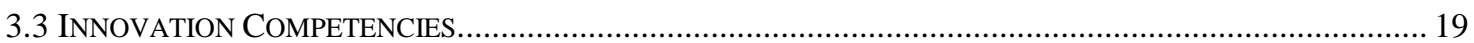

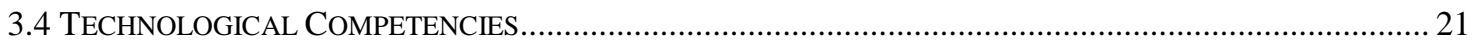

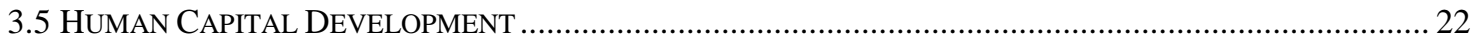

3.6 INCIDENCE OF INNOVATION, TECHNOLOGICAL COMPETENCIES, AND FOCUS ON SKILLS IN THE

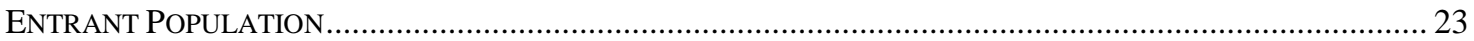

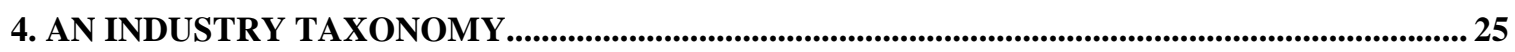

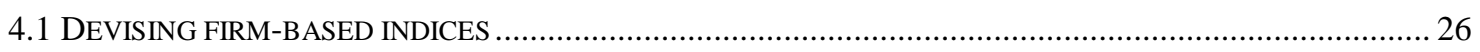

4.2 INDUSTRY DIFFERENCES USING THE COMPETENCY APPROACH …................................................. 30

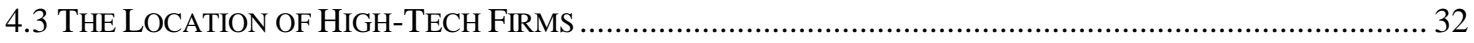

5. A COMPARISON OF FIRM-BASED AND OTHER INDUSTRY-BASED CLASSIFICATION

SCHEMES.................................................................................................................................................................... 33

6. INNOVATION, SKILL INTENSITY, TECHNOVATION: DO THEY HAVE SEPARATE

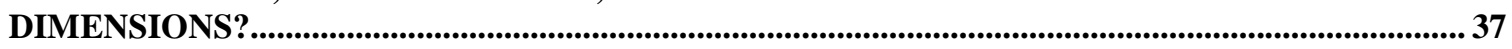

7. CONCLUSION ……….......................................................................................................................................... 46

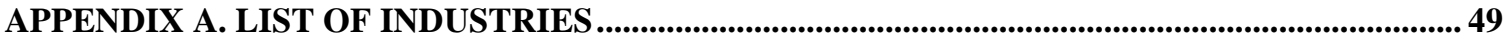

REFERENCES .......................................................................................................................................................... 50 


\section{Abstract}

Considerable attention has been directed at understanding the structural changes that are generating an increased need for skilled workers. These changes are perceived to be the result of developments associated with the emergence of the new knowledge economy, whose potential is often linked to the growth of new technology-based firms (NTBFs). Where are these firms to be found? Related work on changes in technology and innovativeness has been accompanied by the creation of taxonomies that classify industries as high-tech or high-knowledge, based primarily on the characteristics of large firms. There is a temptation to use these taxonomies to identify new technology-based firms only within certain sectors. This paper uses a special survey that collected data on new firms to argue that this would be unwise.

The paper investigates the limitations of existing classification schemes that might be used to classify industries as high- or low-tech, as advanced or otherwise. Characteristically unidimensional in scope, many of these taxonomies employ conceptual and operational measures that are narrow and incomplete. Consequently, previous rankings that identify sectors as high- or low-tech using these measures obscure the degree of innovativeness and human capital formation exhibited by certain industries. In a policy environment wherein emotive 'scoreboard' classifications have direct effects on resource allocation, the social costs of misclassification are potentially significant.

Using a comparative methodology, this study investigates the role that conceptualization plays in devising taxonomies of high- and low-tech industries. Far from producing definitive classifications, existing measures of technological advancement are found to be wanting when their underpinnings are examined closely. Our objective in the current analysis is to examine the limitations of standard classification schemes, particularly when applied to new small firms, and to suggest an alternative framework based on a competency-model of the firm. This framework differs from previous attempts in several important respects. First, it constitutes a multidimensional approach to industry classification. As different concepts - such as innovation, technology use, and worker skills - can be used to define high- and low-tech industries, we integrate each of these measures into a unified framework that captures the different dimensions of technological prowess. This, in turn, lessens the degree of bias that may arise due to narrow or incomplete conceptualization. Second, our competency-based approach focuses directly on the population of interest-new small firms. Often at the forefront of product development and advanced technology use, it is these firms that are seen as critical in the transition to knowledge-based production. Basing industry classification on new small firms thus alleviates the bias in favour of large firm characteristics that arises with the use of industry-level aggregates.

The competency-based approach developed herein reveals several important findings. First, industry rankings are highly sensitive to the conceptual measures that form the basis for classification. Accordingly, classification schemes that rely on a single-measure of technological prowess, as many do, may incorrectly rank industries and/or classify sectors. Second, firms that possess the advanced competencies that contribute to 
technological prowess are found in many industries, and are not as sector-specific as previous attempts at classification suggest. Simply stated, low-tech industries are not devoid of high-tech firms, nor, for that matter, are high-tech industries comprised exclusively of high-tech firms. Consequently, broad generalizations at the industry-level may prove dubious.

An additional issue addressed herein focuses on the appropriateness of using a single competency-based index as a basis for classifying industries. In our view, the competency-based approach represents a considerable advance over previous efforts: it formally recognizes the multidimensional nature of technological prowess, and it focuses on the correct firm population. That said, can we then infer that a single-ranking derived from such a framework provides sufficient grounds for classification? Or alternatively, should a series of rankings be used when attempting such a task? We find that there are numerous dimensions to technological prowess and that the use of any single index may, in fact, obscure some of these. Consequently, different industries will emerge as hightech leaders when different aspects of technological prowess are emphasized.

Keywords: entry, productivity, innovation, exit 


\section{Acknowledgements}

We would like to thank Ted Wannell of the Analytical Studies Branch at Statistics Canada for his helpful comments. We also wish to acknowledge the programming assistance that we received from Daniel Stripinis and Bob Gibson during the preparation of this paper. 


\section{Introduction}

In recent years, considerable attention has been paid to the restructuring that has been taking place in Canadian industries. It has become commonplace to hear that we are moving into a new economy-a knowledge economy where skills, human capital, and innovativeness are prerequisites for success.

New technologies related to the introduction of the electronic microchip have heralded a major change in the way that business is being conducted. This has, in turn, led some to describe the changes that are taking place as being just as momentous as the earlier shifts in industrial technology that were wrought by the steam engine, by electricity, by the telegraph and telephone, or by the internal combustion engine.

The introduction of new computer-based technologies has been accompanied by rapid growth in some sectors. The electrical and business equipment sectors have grown as computer usage has spread, as have business service industries specializing in computer programming and the servicing of computers. New wholesalers and retailers have emerged to exploit the sales of computer equipment.

These developments have focused the attention of academic studies on the growth of new technology-based firms (NTBFs) in sectors that are clearly associated with these new technologies-industries such as semiconductors, computer-aided design, computer software, and biotechnology (Rothwell and Zegveld, 1982). Changes in industrial paradigms are commonly introduced through new small firms. This observation has resulted in the development of life-cycle models by Shimsoni (1970), Abernathy and Utterbach (1978), Gort and Klepper (1982), Klepper and Millar (1995), and Klepper (1996) that formalize this process. Small firms are portrayed as often excelling in the early stages of an industry when product standards are still in a fluid state, when competition is based on new features, when turnover is high, and when production processes have not yet stabilized. In these early stages, small new firms often play a key role in developing new products. It is these firms that can overcome the inertia built into larger firms and take advantage of new technologies. Consequently, these firms are seen to be critical in the transition to knowledge-based production.

Two factors have created a tendency to regard the evolution of these NTBFs as highly industry specific. The first is the high visibility of several of the new rapidly growing sectors. The second is the emergence of a number of classification schemes, such as that used by the Organization of Economic Cooperation and Development (OECD, 1997) that 'score' industries as being high-tech as opposed to low-tech. ${ }^{1}$ Is it true that new technology-based firms are sector specific, as these classification schemes imply, or are they found in many industries? If it is the latter, broad-based policies to encourage their development are more appropriate. If it is the former, sector-specific policies may be required.

\footnotetext{
${ }^{1}$ See OECD $(1994,1997)$.
} 
It is the purpose of the present paper to ask four questions. First, how adequate are existing classification schemes that are used to argue that the new knowledge economy is highly concentrated in some sectors? Second, can a new set of indices be devised that are more appropriate for industry classification? Third, if so, what do these new measures reveal about the identification of high-tech industries and the location of high-tech firms? Finally, what do these indices tell us about the usefulness of classification schemes based on a single industry ranking?

This paper examines these issues, making use of a new data set to investigate how industries differ in the extent to which they contain advanced firms and the extent to which alternate concepts of technological prowess yield different industry rankings. In doing so, the paper develops a multidimensional framework for industry classification based on the advanced competencies of new small firms. We argue that this framework represents an advance over previous efforts, while recognizing that any single ranking derived from this multidimensional index cannot provide the definitive basis for classification.

The paper is organized as follows.

Section 2 examines a series of measures that are commonly used to classify industries as more or less technologically advanced or as being high- or low-knowledge. Three standard measures of technological prowess-R\&D intensity, innovation, and technology usage-are investigated in detail. We argue that each of these measures, when applied alone, is subject to a series of shortcomings that limit the utility of its corresponding taxonomy, both in general and when applied to subsets of the business population such as NTBFs.

Section 3 examines the firm-level characteristics that form the basis for our competencybased framework. Based on survey data, the innovation, technology, and human capital characteristics of new small firms are investigated in detail, as is their incidence within the entrant population.

Section 4 develops an alternative classification scheme using a competency-based framework for new small firms. This method draws on a firm's innovation, human capital, and technology characteristics to produce a multidimensional measure of its technological prowess. In developing this measure, we create three separate indices; each is centered on a strategic dimension of firm behaviour. These are then combined to form an overall index that captures the advanced competencies of new firms in a parsimonious fashion. Two issues are then examined. First, we investigate differences in industry rankings based on the innovation, technology, and human capital indices, respectively. Second, we use these measures to investigate the concentration of high-tech firms in both high- and low-tech industries. 
Section 5 compares our overall survey-based index to existing classification systemssuch as the high-tech/low-tech taxonomy used by the OECD - that are derived from aggregate industry characteristics. We find that these aggregate indices produce different high-tech groupings than our index based on the advanced competencies of new firms.

Section 6 investigates the limitations of a single-index approach to classification. Since the summarization inherent in any index may be too parsimonious, we ask whether the firm-based competency approach should be used to yield a single ranking, or whether it should be used to generate a set of rankings at the industry level. We conclude that there are several different dimensions to technological prowess and that the use of a single index would obscure some of these. We end with the observation that there are many combinations of advanced competencies and that almost every industry ranks highly based on at least one of these combinations. The implication of our analysis is that policy prescriptions that presume that new technology-based firms are confined to particular sectors may, in fact, be misplaced.

\section{Existing Classification Schemes of High-Tech or Knowledge- Based Industries}

The use of nomenclature such as 'knowledge economy' or 'high-tech sector' or 'innovation economy' is not generally accompanied by precise definitions of the phenomenon in question. Failure to specify how the high-knowledge sector is defined leaves discussions about its location empty and vapid. However, specifying which sectors are high- or low-knowledge is a difficult proposition since the very concept of knowledge is hard to define and even more difficult to measure. This is because a knowledge-based industry has a wide range of characteristics. To some researchers, it means an innovative sector where new products and processes are being produced. To others, it means the use of advanced technologies that either have a high degree of complexity or that incorporate advanced scientific and engineering techniques, such as biotechnology. To others, it means the embodiment of high levels of human skills in the production process.

There have been several attempts to systematically define the knowledge sectors of the economy. Some have focused on classifying industries as either high- or low-tech. Others have used a broader construct of high- and low-knowledge industries. In both cases, the criteria that are used involve such variables as the basic skill levels of workers, or the importance of research and development, or the use of advanced technologies.

Most of these studies have focused on broad industry characteristics to classify an industry into one or other category. These approaches have deficiencies, both when classifying all firms in an industry and, in particular, when focusing on new-technology based firms.

First, as we shall argue below, some classification schemes use concepts that are often narrow or incomplete. The OECD's high-tech classification scheme (1997) provides one of the most visible examples of this. 
Second, existing classification schemes often treat industries as homogeneous - that is, all firms in an industry are regarded as the same. While any classification scheme must, by necessity, simplify reality, simplifications may render the classification scheme innappropriate for some purposes. Two examples can be cited.

First, the high-tech classification of an industry should not be used to classify all firms therein by their degree of technological competence. ${ }^{2}$ In reality, an industry is made up of many different types of firms-some of which are more advanced than others. Some firms in low-tech industries may have greater technological skills than the average firm in a high-tech industry. Classification schemes that refer to a whole industry as low-tech may be used to unfairly characterize all firms in an industry as low-tech whereas, in reality, some of those firms may be extremely advanced technologically.

Second, the classification schemes may be inappropriate for particular firm subpopulations-for example, new small firms. Small and large firms differ in many respects. Audretsch (1995) has observed that the large- and small-firm innovation rates at the industry level are not closely correlated. Using an average industry variable, whose value is generally determined by the larger firms in the industry, will not classify small firms correctly if their characteristics differ systematically from those of larger firms. This is a serious deficiency when a classification scheme is needed to specify the location of the small, new firms that are often seen as providing the core dynamics of the new knowledge sectors.

This paper examines whether existing classifications that purport to measure technological prowess are adequate. This topic is important. The terms 'high-tech' and 'knowledge-based' have emotive connotations. High-tech industries are seen to be good and desirable; low-knowledge sectors are associated with the 'old' economy and thus are undesirable. Therefore, the stakes are high when a whole sector receives the emotive classification of low-knowledge, or low-tech. For example, the OECD (1996a, 1996b, 1997) now publishes detailed 'score' sheets that record which countries are expanding their employment in 'high-tech' sectors. There will be a tendency for national governments to rank the success of their industrial policies on the basis of these 'scoreboards'. Governments are increasingly concerned about the extent to which their national economies are making the transition to the new knowledge economy. Papers are being written to suggest that government funding be directed to strengthening high-tech sectors. Thus, the separation of industries into 'good' and 'bad' promises to have concomitant effects on program spending and the direction of subsidies. If the OECDtype classification schemes that are presently being used provide guides that are misleading, inappropriate, or applicable only in limited circumstances, public policy will be poorly served.

There is a parallel between issues that emerge when we ask whether there are high- as opposed to low-knowledge industries and the issues that were addressed in a previous debate about industrial policy and the necessity of identifying winning sectors. At one

\footnotetext{
${ }^{2}$ This is done when the availability of support programs is conditioned on whether a firm is found in a particular high-tech industry.
} 
time, the latter discussion focused almost exclusively on identifying growing as opposed to declining industries - so as to facilitate the picking of 'winners'. Earlier work by Baldwin and Gorecki (1993) and Davis and Haltiwanger (1992) demonstrated that firms are growing and declining in almost all sectors. Most job turnover (job gains and job losses) that occurs as a result of restructuring is associated with intra-industry rather than inter-industry change. ${ }^{3}$ Even in declining sectors, there is new entry and considerable expansion on the part of some firms. A policy that ignored how widespread growth is, even in declining industries, would ignore firms that are important contributors to job growth.

While those who advocate that governments pick winners no longer talk of growth and decline as just a sectoral phenomenon, those who advocate the desirability of having more rather than less high-tech firms, and associate this goal with the need to support only certain industries, often have not absorbed the results of this other literature. They have not yet drawn the inference that many firms in low-tech sectors may be growing because they are innovative.

The problem with the high-tech or knowledge-based classification schemes that have come into vogue is not that their use just tends to ignore the high-tech firms in low-tech sectors, but also that their narrow focus may incorrectly classify sectors. An R\&D based classification scheme may not correspond to a more comprehensive definition that considers both inputs to the innovation process and outputs of the innovation process. Or it may have little to do with the extent to which the work force of an industry is highly skilled. Or it may not be closely related to the extent to which sectors create or make use of advanced technologies.

The rest of this section describes three different approaches to classification in detail. In a subsequent section, we develop our own taxonomy based on a broader variety of indicators than any of these consider. But prior to doing so, we will explain what others have done and discuss the shortcomings of these approaches-shortcomings that we attempt to overcome in deriving our own indices.

There are at least three different concepts of technological prowess found in various classification schemes that are used to categorize industries as advanced or otherwise. These involve R\&D, innovation, and the use of advanced technology. Each of these will be discussed in turn.

\subsection{Intensity of R\&D as Technological Prowess}

The high-tech classification scheme that is used by the OECD is based primarily on the R\&D intensity of an industry. ${ }^{4}$ Using R\&D-to-sales ratios, the OECD divides certain industries into high-, medium-, and low-tech for several studies. This approach suffers from a number of deficiencies.

\footnotetext{
${ }^{3}$ See Baldwin (1995: 147-49) for a comparison of Canadian and U.S. experience in this regard.

${ }^{4}$ See OECD (1997), pp. 69 and 109.
} 
First, while it is offered as a technology-scheme, it is not a direct measure of at least one aspect of the technological prowess of an industry. Technology involves the use of advanced processes-either equipment such as flexible manufacturing cells or practices such as rapid prototyping - that often require the use of advanced systems associated with $\mathrm{CAD} / \mathrm{CAM}$ design and engineering systems. These are ignored in this classification scheme. Nor does it capture the skill levels of the work force that are essential to growth in new firms (Baldwin, 1998).

Second, it measures inputs that are used to produce innovations and not the innovations themselves. Moreover, $R \& D$ is only one of the inputs to the innovation process. While it might still be argued that a taxonomy based only on $R \& D$ is useful for classifying industries by the extent to which they make investments in knowledge, even this position relies too heavily for its justification on the now discredited view that innovation is a linear process with $\mathrm{R} \& \mathrm{D}$ forming the first and only starting point. Work on innovation systems and innovation surveys have forced a reevaluation of this position by emphasizing how widespread are the sources of ideas for innovation outside R\&D labs. Baldwin and Da Pont (1996) show that the R\&D process is only one of many that contribute to innovation in Canada. Academic research emphasizes that substantial discoveries have been made outside of R\&D labs in engineering or processing divisions. These discoveries have led to important innovations. Mowery and Rosenberg (1989) have stressed that many innovations have originated not in R\&D laboratories but on the production line where practical production problems have to be solved. Using R\&D to define a technologically advanced industry will misclassify industries that make their advances outside of organized $R \& D$ labs if the two processes are given different emphases across industries. Others have made the same point using industry level data on different aspects of the innovation process. Audretsch (1995) concludes that measures of innovation, $R \& D$ inputs, and patents for the United States do not rank industries in the same way. Äkerblom, Virtaharju and Leppälahti (1996) make the same point for Finland.

Third, the official statistics on R\&D miss some important activity. ${ }^{5}$ Kleinknecht, Poot and Reijnen (1991) argue that informal R\&D is an important input into the innovation process and that it is generally omitted in the R\&D data that are used by the OECD-since the Frascati manual demands that $R \& D$ has to be a continuous activity. This has particular importance for countries whose industrial structure consists of smaller firms, since these firms tend to do more informal R\&D (Kleinknecht, Poot and Reijnen, 1991). Baldwin (1997b) confirms that in Canada small firms are more likely to conduct R\&D on a discontinuous basis.

Fourth, $R \& D$ is more likely to be found behind some innovations than others. $R \& D$ is more likely to be associated with product than with process innovations (see Baldwin, Sabourin and Hanel, 1998). More importantly, small firms are more likely to use production and engineering facilities than R\&D departments. This means that a simple

\footnotetext{
${ }^{5}$ Schmookler (1959) raised this issue in a debate over whether, on the basis of official R\&D statistics, it was correct to conclude that small firms were less innovative than large firms. He argued that informal R\&D was more prevalent in small firms and that its incidence was not highly correlated with formal measures of R\&D.
} 
R\&D-based index will understate the relative importance of industries where process innovation is more important and where small firms account for a larger percentage of employment.

Fifth, the variable that is used to measure the intensity of research and development is poorly suited statistically for the purpose of classification. A variable is an ill suited basis for classification if it has little variance. The OECD intensity measure is plotted in Figure 2.1.1 for 22 manufacturing industries. For most of the sample, there are only small differences in the classification variable. In this situation, measurement errors such as those associated with an omission of activities would suffice to reverse the ranking of some of these industries.

\section{Figure 2.1.1 Inter-industry R\&D Intensities}

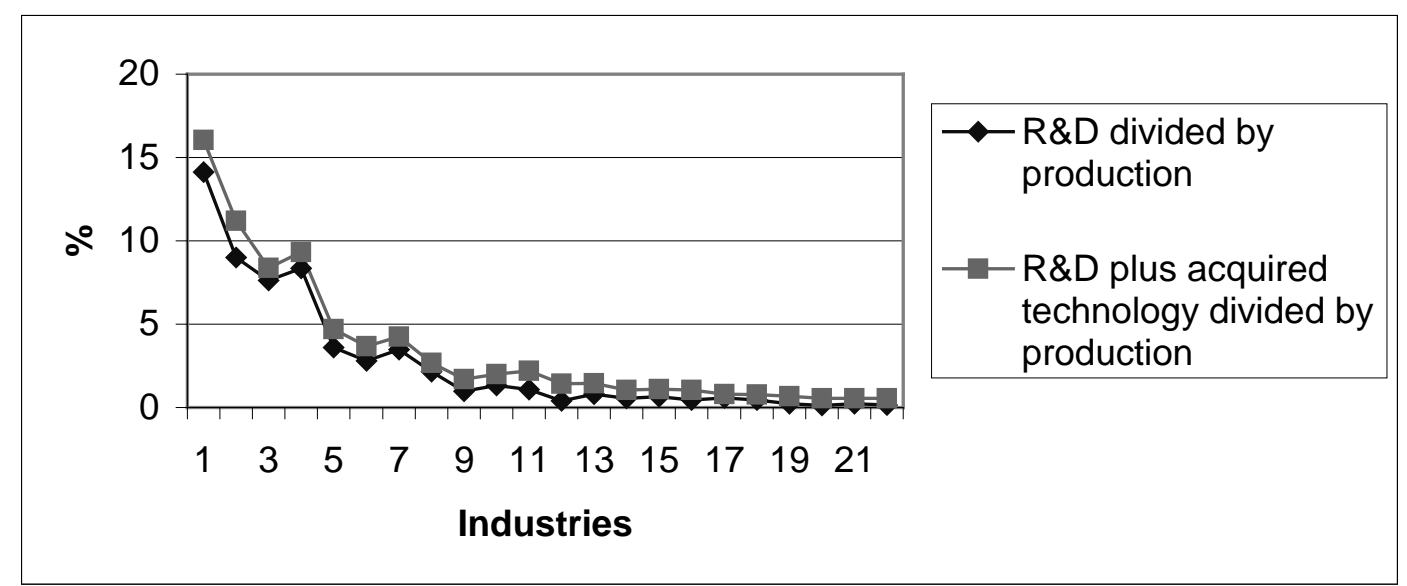

Source: OECD (1997, p.110).

Finally, the OECD classification scheme focuses exclusively on the manufacturing sector and ignores the services sector. This bias in favour of the goods sector leaves a void in our understanding of the determinants of overall growth since the manufacturing sector accounts for less than $20 \%$ of employment in Canada. Innovations in services have an important effect on social welfare. Services sectors such as transportation, communications, utilities, retailing, and computing services have all been introducing innovations that not only directly affect consumers but also feed into the productivity of goods industries. What is more, new small firms are more prevalent in the services than in the manufacturing sector. A study of NTBFs is incomplete without consideration being given to the services sector.

\subsection{Innovation as Technological Prowess}

To overcome the possible distortion occasioned by an emphasis on R\&D inputs alone, the technological prowess of a firm could be defined as its ability to innovate. Innovation and technological prowess are closely associated in the minds of most people. If we are ultimately interested in the extent to which new products and processes are introduced 
(because of our interest in growth, productivity, or competitiveness), then it is more sensible to focus on the outputs of the innovation process than on inputs like R\&D. ${ }^{6}$ While this principle is relatively uncontroversial, translating it into practice, however, is difficult. This means that indices based on a single measure of innovative output should be treated with caution.

The innovativeness of a firm can be measured in several ways. Robson, Townsend and Pavitt (1988), for example, used a database of major innovations produced by the Science Policy Research Unit (SPRU) at the University of Sussex to classify industries by their tendency to innovate. The list of innovations was assembled by a panel of 'experts' and consisted of 4378 innovations made over the period 1945-83. Each innovation was classified by the industry where it originated and whether it was used in that industry or another. Robson, Townsend and Pavitt (1988) also examined the pattern of innovations derived by Scherer (1982) based on patented inventions of 443 large U.S. companies in 1974. The UK/US patterns are reported in Table 2.2.1 and are divided into three sectors: the core sector, which consists of chemicals, machinery, mechanical engineering, instruments, and electronics; the secondary sector, which consists of metals, electrical engineering, shipbuilding/offshore engineering, vehicles, building materials, rubber and plastic goods; and a residual 'other' category, which consists of the remainder of the industries-textiles, paper, food, beverages, furniture, wood, leather, printing, and clothing. An innovation is referred to by Robson, Townsend and Pavitt (1988) as 'technology produced'. Innovations that are produced in one sector and used in another are called 'product' innovations. Innovations that are produced and used in the same sector are called 'process' innovations.

Table 2.2.1. Comparisons of Innovation Patterns in the United Kingdom and the United States

\begin{tabular}{|c|c|c|c|c|c|c|c|c|}
\hline & \multicolumn{2}{|c|}{$\begin{array}{l}\text { Percentage of } \\
\text { 'Technology' } \\
\text { Produced }\end{array}$} & \multicolumn{2}{|c|}{$\begin{array}{c}\text { Ratio of 'Product' } \\
\text { to 'Process } \\
\text { Technology } \\
\text { Produced }\end{array}$} & \multicolumn{2}{|c|}{$\begin{array}{l}\text { Percentage of all } \\
\text { 'Technology' used }\end{array}$} & \multicolumn{2}{|c|}{$\begin{array}{l}\text { Percentage of all } \\
\text { 'Product' } \\
\text { Technology used }\end{array}$} \\
\hline & UK & US & UK & US & UK & US & UK & US \\
\hline Core & 68.3 & 62.8 & 3.26 & 2.64 & 18.3 & 18.8 & 3.3 & 2.3 \\
\hline Secondary & 20.6 & 23.9 & 1.30 & 2.10 & 16.4 & 12.7 & 11.1 & 7.3 \\
\hline Other Manufacturing & 8.3 & 12.0 & 0.45 & 1.04 & 26.0 & 11.4 & 30.4 & 8.0 \\
\hline Non-manufacturing & 2.9 & 1.3 & 0.16 & 0.29 & 39.4 & 57.1 & 55.1 & 82.4 \\
\hline All Groups & 100 & 100 & & & 100 & 100 & 100 & 100 \\
\hline
\end{tabular}

Source: Robson, Townsend and Pavitt (1988).

The core sector is highly innovative in that it produces the majority of technological innovations of both types (column 1). Since the ratio of 'product' to 'process' innovations is highest in the core sector (column 2), this group produces more innovations than it uses. Thus some industries may be classified as more innovative in that they produce more innovations than they use. However, if the distribution of 'process' innovations is examined (column 3), the sectors are more equal in importance than if 'product'

\footnotetext{
${ }^{6}$ Unless, of course, the two are so closely linked that one is a perfect proxy for the other.
} 
innovations are compared (column 4). The inter-industry differences then are found more on the product than on the process side of innovation.

A second expert database has been constructed by The Futures Group for the Small Business Administration (Acs and Audretsch, 1990). This database consists of 8,074 innovations made in 1982 that were put together from technology, engineering, and trade journals in manufacturing industries. When the innovations are assigned to their industry of origin, quite a different picture emerges about the relative importance of the different sectors than is given by the SPRU database. For example, the chemicals, drugs, petroleum, machinery, computers, industrial electrical equipment, communications, and instruments industries (roughly Robson's core sector) together account for only $13 \%$ of all innovations produced (Audretsch, 1995, Table 2.8). A reason for the difference in the two distributions may be that a more inclusive definition of innovation is used in the Small Business Administration (SBA) database. When the innovations in the SBA database were classified by their degree of originality, over $85 \%$ were found to be only modest improvements designed to update existing products-less than $12 \%$ involved significant innovations (Audretsch, 1995, Table 2.7).

While focusing on the outputs of the innovation process provides an inherently more satisfactory procedure than a method that just focuses on inputs, this method is not without its drawbacks. First, the use of lists of innovations, as was done by both the SPRU and the SBA, involves considerable subjectivity-even when assembled by a panel of experts. Innovations range from the most pathbreaking to the more mundane. Which industries are the most innovative depends heavily on the cut-off point used to distinguish the difference between the more important and the less important. Moreover, the comprehensiveness of the list of innovations generated by these literature-based searches is difficult to evaluate. One bias is readily acknowledged (Kleinknecht, Reijnen and Smits, 1993). Lists of innovations that are drawn from trade publications will be dominated by product innovations and will underrepresent process innovations.

Two European studies that are based on trade-journal surveys confirm that the types of innovations that are captured cover a wide gamut. Kleinknecht, Reijnen and Smits (1993) collected a sample of innovations introduced in the Netherlands in 1989 and classified them as being totally new, modestly improved, a new or improved accessory of an existing product, or simply a product differentiation. Of the 1,242 domestically developed innovations, only $3.6 \%$ were totally new, $49.2 \%$ were modestly improved and $41.3 \%$ involved only product differentiation.

A complementary study by Fleissner, Hofkirchner and Pohl (1993) for Austria found 1,355 innovations introduced by both foreign and Austrian enterprises in 1989. Only $17.5 \%$ were completely new products, $20.5 \%$ involved moderately changed products, $25.2 \%$ were products with changed parts, and $29.6 \%$ were new products that involved simple product differentiation from older products.

Instead of using expert panels or trade-journal tabulations, firm-based surveys of innovation can be employed to examine inter-industry differences in innovation tendencies. Examples of these surveys are to be found in those being undertaken by the 
European community (the Community Innovation Surveys-CIS). These surveys rely on a firm to identify itself as an innovator or a non-innovator and to indicate the type of innovation being introduced. These surveys are far more inclusive than investigations that rely upon drawing up a specific list of highly visible innovations. This is an advantage when it comes to coverage; it may, however, suffer from the disadvantage that it leads to a lack of precision in the definition of an innovation. While the surveys define innovation to involve only a major breakthrough for the firm, few of the surveys investigate at any length the extent to which the innovations being reported were indeed major-or, more importantly, what the firm considers to be major.

The few exceptions find a considerable range being reported — as did the Futures Group when it examined the trade literature for announcements of new products. In the same vein, the 1993 Canadian innovation survey investigated whether the major innovation of the firm was a world-first, a Canadian first, or fell into a residual category (Baldwin and Da Pont, 1996). Only $16 \%$ were world firsts - a percentage that is not dissimilar to that found in the SBA database. More importantly, the innovation regime (the profile of a firm's technological capabilities) varied substantially across the various innovation types. This implies that there is a continuum of firms with different capacities within an industry - that the population of innovators is heterogeneous, not homogeneous.

Since innovations are so varied, there is no single measure of innovativeness that innovation surveys or trade journal searches should be expected to yield. It is not sufficient to argue that this could be resolved by specifying that it is only major, breakthrough innovations that should be included in the definition of an innovation, since it is only major breakthroughs that should interest us. Even if this position is taken, this still leaves the problem of clearly defining 'major'. Moreover this argument ignores the important contribution that marginal innovations make. Hollander (1965), for example, studied the course of productivity growth in Dupont's rayon division and found that much of the productivity growth therein was attributed to marginal innovations.

The second deficiency arising from a pure innovation-based taxonomy stems from the response bias that is likely to favour industries in Robson's core sector at the expense of the secondary and other sectors. Product innovations involve distinct discontinuous change. They are, therefore, more likely to come to mind and be enumerated by respondents than process innovations that are more likely to involve incremental change. Process innovations often start by adding a new machine to the capital stock in the plant. Other machines are reorganized. Bottlenecks are then removed and different parts of the production process are better integrated. Survey respondents may not regard these types of changes as sufficiently momentous to warrant being characterized as an innovationeven though the cumulative effect of these changes may be large. Yet, these types of changes may have just as large an effect for the secondary and other sectors of Robson's classification scheme as do product innovations for the core sector. Data that are skewed towards product innovations will incorrectly attribute innovativeness to the industries that have relatively more product than process innovations. This is likely to lead to a false 
impression that suggests the innovation process is concentrated in just those industries that favour product innovations. ${ }^{7}$

It is inappropriate to suggest that industries where momentous-type product innovations arise are more innovative than those industries that slowly incorporate these products into their production processes. ${ }^{8}$ What is produced in one industry is consumed in other industries-either as an intermediate product or as a capital good input. And incorporating the new product into the using industry is far from an easy task. The using firms also have to be innovative; it is just that they are more often innovative with regard to processes or materials than in terms of products. Incorporating innovations is difficult, requires substantial skills, and is often done slowly in incremental steps. For example, the electric motor had been invented prior to 1900; but it accounted for only $7 \%$ of total horsepower used in the Canadian manufacturing sector in 1900. This slowly increased to $74 \%$ over the succeeding thirty years. ${ }^{9}$ Incorporating the new technology was not easy. Firms had to find a way to introduce it alongside existing technologies. They had to design new plants. They had to mesh it with existing capital equipment. All of this took new investment in both plant and equipment as well as changes in plant layout and relocation of original plants away from water courses and closer to sources of electricity. In the same vein, it has taken many companies time to integrate the computer effectively into their operations. Computers alone do not run businesses. Software has to be written and business practices have to be changed. Doing this is difficult. For example, software considerations rank high on the list of impediments to the adoption of advanced technologies (Baldwin, Sabourin and Rafiquzzaman, 1996).

In summary, innovation is multidimensional. Sometimes it involves new products; other times it consists of new processes. Innovations can vary widely in terms of their novelty. It is best, therefore, not to rely on a single measure of the innovativeness of an industry when developing classification schemes. Rather, various dimensions should be measured and weighed against one another.

\subsection{Technology Use as Technological Prowess}

As attractive as innovation is as a measure of how advanced an industry is, it does not directly capture the extent to which an industry's production processes incorporate advanced technologies. Innovation classifications may readily miss the extent to which firms are incorporating the latest machinery and equipment into their plants since the purchase of this equipment is often not considered to involve the creation of an innovation. Nevertheless, being able to incorporate advanced equipment into the production process is a mark of a firm's technological prowess.

\footnotetext{
${ }^{7}$ As pointed out in the previous section, this bias also arises from the use of the OECD-type R\&D index.

8 It is important to note that the classification scheme developed by Robson, Townsend and Pavitt (1988) was not used by them for this purpose. They were interested in how this system could be used to understand the flow of products from one sector to another.

${ }^{9}$ See Baldwin, Diverty and Sabourin (1995).
} 
The introduction of advanced technologies requires the use of advanced equipment, its organization into new processes, and the application of what is often specialized knowledge. As such, it is difficult to measure the intensity of advanced technology useespecially in a fashion that facilitates comparisons across industries.

Several surveys have been conducted in Canada, Australia and the United States to estimate the intensity of use of a set of advanced types of equipment or processes that are associated with advanced technologies. ${ }^{10}$ These are technologies such as computer-aided design and engineering, flexible manufacturing cells, computer numerically controlled machines, materials-working lasers, robots, automated inspection equipment, local area networks, programmable controllers, computer-integrated manufacturing systems and artificial-intelligence systems.

Most of these technologies are based on the microchips that are at the centre of what many describe as the new technological revolution. At the heart of this revolution are advances that have been made in microelectronics. Computers are transforming the technology set and changing the way in which manufacturing establishments do business - by changing the way products are designed and engineered, the cutting and shaping of parts, the assembly process, the planning and control of material requirements, and the integration of these various processes.

The new industrial revolution is associated not just with the spreading use of stand-alone computers, but also with their integration into other goods and their combination with services. Chips and computers are being increasingly embedded into machines and processes. Computer-based technologies have penetrated all parts of the production process. Computer-aided design and engineering is used in the early stages as products are planned. Numerically controlled (or computer numerically controlled) machines are part of the cutting and assembly process. Computers aid the communication and inspection process, either by providing information through local area networks (LANS) or through computers on the factory floor. Computers are also basic to materials-planning systems. But even here it is not computers alone but systems of hardware and software that matter. The practice that has facilitated just-in-time inventory practices-materials planning - combines both hardware and software. Software costs often far outweigh the cost of the computer equipment that is used in the advanced technological process. Software is often created by the user, who by doing so manufactures a new technology that is firm- and process-specific. As such, the user is as much an innovator as is the firm that builds the advanced equipment. Finally, computers may have stimulated the development of individual components of the production process, but they are also central to those systems that bring components together into an integrated whole. Integrated systems are key to melding the new flexible manufacturing cells into the production line.

\footnotetext{
${ }^{10}$ See Australian Bureau of Statistics (1989), Baldwin and Sabourin (1995), and U.S. Bureau of the Census (1989).
} 
The importance of these new computer-based systems can be estimated using information on the use of 22 advanced technologies that is available from the results of the Survey of Innovation and Advanced Manufacturing Technology (SMT) conducted by Statistics Canada in 1993. The incidence of use, defined as the percentage of shipments in plants using an advanced technology, can be employed to compare how technologically advanced are different industries. The adoption rates for the 10 leading technologies are given in Table 2.3.1 and are sorted by the average adoption rate across the leading technologies (column 13). The core/secondary/other sectors from the innovation classification are identified in column 2.

It is apparent that the first two sectors-the core/secondary-are generally ranked towards the top of the list and the industries in the 'other' sector are ranked towards the bottom. However, two industries that are only classified as secondary on the basis of their 'innovativeness' (primary metals and transportation) are in the top three based on the intensity of advanced technology use. Moreover, three of the 'other' industries-paper, food, and miscellaneous manufacturing — place in the middle five. Non-metallic minerals, rubber, and fabricated metal products would rank in the middle five on the basis of innovation intensity, but here are in the bottom seven when based on advanced technology use.

It is clear that industry rankings based on innovative output and the extent of advanced technology use are related—but imperfectly. Industries such as primary metals and transportation, which rank in the second rung of innovative industries using Robson's classification scheme, are actually among the most technologically advanced. Industries such as machinery, which are among the first rank of innovative industries, are only in the second rank of the technologically advanced. Industries such as paper and food, which are the least innovative, fall in the second rank on the basis of technology use.

It should be stressed that no list of technologies can be complete. For example, the Canadian survey covered only 22 major technologies. Some of these technologies are not as relevant to some industries as others. Those industries where the list is less relevant (e.g., printing and publishing) will, therefore, rank lower for this reason, as opposed to their being technologically backward. This simply emphasizes the caution that should be used in employing any of the indices alone-whether it be an R\&D, an innovation, or a technology index - to rank industries as high-tech or low-tech. 
Table 2.3.1. Advanced Computer-Based Technologies (\% of establishments—shipment weighted—using technologies)

\begin{tabular}{|c|c|c|c|c|c|c|c|c|c|c|c|c|}
\hline Industry & Sector & CAD/CAE & $\begin{array}{c}\text { Programmable } \\
\text { Controllers }\end{array}$ & \begin{tabular}{|c|} 
Factory \\
Computers
\end{tabular} & \begin{tabular}{|c|} 
Requirement \\
Planning
\end{tabular} & $\begin{array}{c}\text { Technical } \\
\text { LANs }\end{array}$ & $\begin{array}{l}\text { Factory } \\
\text { LANs }\end{array}$ & $\begin{array}{c}\text { Inspection } \\
\text { of Final } \\
\text { Products } \\
\end{array}$ & \begin{tabular}{|c|} 
Manufacturing \\
Resource \\
Planning
\end{tabular} & SCADA & $\begin{array}{c}\text { Inter- } \\
\text { company } \\
\text { Networks } \\
\end{array}$ & Average \\
\hline Primary Metals & Secondary & 90 & 80 & 89 & 70 & 76 & 76 & 74 & 68 & 64 & 71 & 75.8 \\
\hline Electrical & Core & 86 & 70 & 68 & 76 & 70 & 65 & 57 & 65 & 57 & 63 & 67.7 \\
\hline Transportation & Secondary & 75 & 61 & 62 & 65 & 60 & 53 & 41 & 53 & 32 & 57 & 55.9 \\
\hline Petroleum & Core & 66 & 71 & 66 & 60 & 71 & 51 & 52 & 44 & 59 & 17 & 55.7 \\
\hline Paper & Other & 74 & 62 & 52 & 26 & 38 & 44 & 49 & 16 & 35 & 32 & 42.8 \\
\hline $\begin{array}{l}\text { "Other" } \\
\text { Manufacturing } \\
\end{array}$ & Other & 67 & 55 & 50 & 38 & 57 & 30 & 14 & 47 & 11 & 14 & 38.3 \\
\hline Food & Other & 45 & 64 & 41 & 48 & 33 & 23 & 36 & 22 & 26 & 28 & 36.6 \\
\hline Machinery & Core & 74 & 44 & 52 & 42 & 35 & 13 & 23 & 25 & 13 & 29 & 35.0 \\
\hline $\begin{array}{l}\text { Non-metallic } \\
\text { Products }\end{array}$ & Secondary & 23 & 54 & 45 & 39 & 16 & 40 & 42 & 1 & 41 & 41 & 34.2 \\
\hline Textiles & Other & 44 & 16 & 32 & 23 & 18 & 25 & 16 & 18 & 25 & 22 & 23.9 \\
\hline Rubber & Secondary & 36 & 42 & 29 & 25 & 26 & 22 & 14 & 17 & 15 & 12 & 23.8 \\
\hline Wood & Other & 28 & 44 & 32 & 6 & 30 & 32 & 11 & 4 & 17 & 15 & 21.9 \\
\hline Printing & Other & 26 & 7 & 33 & 23 & 7 & 14 & 15 & 20 & 20 & 9 & 17.4 \\
\hline Furniture & Other & 42 & 17 & 9 & 33 & 6 & 9 & 7 & 17 & 5 & 0 & 14.5 \\
\hline $\begin{array}{l}\text { Fabricated Metal } \\
\text { Products }\end{array}$ & Secondary & 42 & 21 & 13 & 25 & 10 & 2 & 3 & 13 & 2 & 10 & 14.1 \\
\hline
\end{tabular}

Source: Baldwin and Sabourin (1995). 


\section{A Competency-Based Approach}

\subsection{Measurement of Industry Competencies}

As the previous discussion has recounted, technological prowess has different meanings to those who have attempted to develop classification schemes that can be used to study differences across sectors and industries. Therefore, taxonomies that are aimed at classifying industries by a measure of advanced technological prowess have alternative standards from which they can choose. The taxonomy may focus on innovative output. Alternately, it may concentrate on some aspect of the production process-whether firms perform research and development, whether their production processes and equipment are advanced technologically. In addition, a taxonomy could focus on whether firms employ workers with higher skill levels. Skilled labour has been recognized as being critical for the implementation of new technology (Bartel and Lichtenberg, 1987). Others have noted the impact of the new technologies on wage differentials that relate to skills in the U.S. (Bound and Johnson, 1992; Berman, Bound and Griliches, 1994; Doms, Dunne and Troske, 1997). Baldwin, Gray and Johnson (1997) and Baldwin and Rafiquzzaman (1998) show that there is a strong connection between the use of advanced technologies and plant wage rates in Canada. These studies suggest that consideration also be given to the presence of skilled labour when defining those industries that have the most technological prowess.

Previous exercises have had several deficiencies. First, they have tended to adopt a very partial analysis. In doing so, they have presumed that there is a single taxonomy that adequately summarizes the characteristics that define advanced technological prowess. Yet it is clear that there is more than one characteristic that defines a new hightechnology firm. Advanced firms capture our attention for a number of reasons: they are innovative; they produce new products; they introduce new processes. To do so, they often employ advanced technologies - either those that they develop themselves or those that they adapt from elsewhere. To produce these new products and processes, they make use of the latest in scientific knowledge. To do so, they require employees with advanced knowledge skills. All of these relate to advanced competencies in a firm. By examining the extent to which these competencies exist in new firms, progress can be made in formalizing what has been until now a somewhat amorphous classification exercise.

The resulting measures can then be used to ask whether only some industries deserve to be treated as advanced on the basis of new firms, or whether new firms in all industries possess unique technological skills. These competencies may vary across industries. New firms in some industries may specialize in only one competency. New firms in others may combine several. For example, new firms in one industry may have a very highly skilled labour force but few advanced technologies. New firms in another may exhibit the reverse. New firms in still another may combine competencies (i.e., labour skill and technological use) but the level of the two competencies in the industry where they are combined may each be below the level found in specialist industries. There is no obvious way to rank these industries against one another. Admittedly, the measures can be combined by adopting a weighting scheme such as a simple average. But there is little to 
guide us as to whether the weights implicit in a simple arithmetic average are appropriate. Fortunately, there are statistical tools that allow us to investigate whether measures of the different advanced competencies are so closely related that they can be combined in a simple aggregate.

We can also ask whether previous taxonomies that make use of aggregate industry characteristics are adequate for the study of inter-industry differences in the characteristics of newly born firms. Studies that use aggregate industry characteristics to investigate where new high-tech firms are found presume that industries are homogeneous - that a single characteristic is adequate for classifying both large and small firms. Studies of small-firm behaviour need industry characteristics that are relevant to their market segment. Because of the skewed nature of firm-size distributions, average industry characteristics like R\&D-to-sales ratios are derived primarily from the $\mathrm{R} \& \mathrm{D}$ profile of large firms. Intra-industry differences in various competencies, such as technology use, across size classes are often large and vary by industry (Baldwin and Sabourin, 1995). Choosing average industry characteristics may, therefore, be inappropriate if we are interested in describing inter-industry differences in the nature of innovation in the small-firm segment.

In the remainder of this paper, we move beyond the very simple partial analysis that is based primarily on a single variable such as $\mathrm{R} \& \mathrm{D}$, or simple measures of innovation, and develop a classification scheme based on a number of competencies that are recognized as being critical to the success of new technology-based firms.

\subsection{Data and Definitions: The Survey of Operating and Financing Practices}

In order to study the advanced competencies of newly born firms, we make use of firmlevel data on entrants to examine the nature of their innovation capabilities. The firmlevel data are taken from Statistics Canada's 1996 Survey of Operating and Financing Practices, which focuses specifically on new smaller firms in both goods and services industries. The focus on new firms permits us to examine the conditions in that segment of the market where most new employment is being created. ${ }^{11}$ The focus on new firms permits us to examine the innovation capabilities of entrants - the group of firms that is often seen to provide new ideas on products and production processes. The inclusion of new firms in both the goods and services sectors overcomes the traditional manufacturing industry bias that has been associated with studies of NTBFs. The richness of the survey database allows both output and input-based measures of innovation, technological, and skill-based competencies of smaller firms to be developed, which are then used to characterize industries by an average measure of advanced competencies.

${ }^{11}$ See Picot, Baldwin and Dupuy (1994). 
The survey focused on new entrants that emerged from childhood and survived to their early teen years-11 to 14 . This population is dominated by small firms: $75 \%$ of these firms have fewer than 20 employees; $16 \%$ have between 20 and 24 employees; $6 \%$ have between 25 and 49 employees, leaving only 3\% with between 50 and 99 employees. In light of the high death rate of new firms, these are the more successful entrants. The frame consisted of all entrants to the commercial sector (both goods and services) in the period 1983-86 that survived to $1993 .{ }^{12}$ The sample included 3,991 firms from both the goods and services sectors. The response rate to the survey was $80 \%$.

The survey provides a broad overview of the financing and operating practices of entrants. The questionnaire contains information on 1) management - the extent of managerial and industry experience and the degree of ownership in the firm; 2) the nature of the competitive environment-whether products quickly become obsolete, whether production technology changes rapidly, whether the threat of new entry is high; 3) the firm's competencies in the area of management, technology, human resources, financing, marketing and production, with special attention paid to various facets of competencies in each area; 4) the extent of financial planning; 5) the importance of investment in R\&D, technology, and training; 6) whether the firm engaged in formal training; and 7) the manner by which various activities were financed.

In order to study the innovation capability of successful entrants and to address the deficiencies of previous classification schemes that arise from their partial nature, we make use of several questions in the survey that capture the concepts that have been used to define technological prowess. These are the innovation capabilities of firms, their human-resource competencies, their technological capacities, and their competitive strategies. Each of these will be used to define the extent to which new firms followed an innovation, a technovation (an advanced high-tech input strategy) or a knowledge (a skill-based) strategy.

There are two types of questions that are used to provide information on the competencies of entrants. First, there are questions that characterize an entrant as following certain strategies-as producing a product innovation, as having formal training programs, or the percentage of investment devoted to $R \& D$ or to training. These take on 0-1 values or are expressed as percentages. Second, there are answers to questions about the entrant's emphasis placed on factors, such as R\&D capabilities or training activities, that contributed to the ongoing success of the firm. These questions were scored on a five-point Likert scale of 1 (low importance) to 5 (high importance). These are used here to gauge the entrant's competencies. ${ }^{13}$ In what follows, entrants are deemed to possess a particular competency or to be stressing a particular strategy if they score that strategy as 4 or 5 on the five-point Likert scale.

\footnotetext{
${ }^{12}$ In addition, the sample of entrants had to have financial data available from administrative records.

${ }^{13}$ Where possible, the two sets of questions were cross-tabulated in order to validate the nature of the Likert scale. For example, there is a high correlation between the importance given to R\&D and the per cent of investment devoted to R\&D—or the score given to training and whether a firm had implemented a formal training program (See Baldwin, 1998). This has also been found in previous surveys that ask firms to score their competencies and to indicate the intensity of their activities (Baldwin, Chandler, Le and Papailiadis, 1994).
} 
While the entrant survey offers a wide and varied set of questions that can be used to gauge the technological prowess of entrants, there are potential problems that should be addressed. First, many of the questions are subjective. The potential problems with subjective questions are well known. The most important is that subjective questions dealing with subjects that are inherently difficult to evaluate or out of the range of a respondent's experience provide information that is unreliable. The classic example is a question that asks subjects to rank various shades of blue by their 'blueness' or asks subjects to rank their abilities to perform a task with which they are unfamiliar.

Although many of the questions included in this survey are subjective, they fall within the range of experience of the managers of new firms. The questions that deal with the magnitude of competitive forces and importance of competencies in various areas are all questions that business managers ask themselves on an ongoing basis. Competitive forces require firms to compare themselves against their competitors. The practice of benchmarking, for instance, has led many firms to assess themselves against industry leaders on a continual basis.

In order to minimize ambiguity, the questions in the survey were all tested extensively. Some questions were taken from previous surveys. The survey also addressed the subjectivity problem by including objective measures of activity in areas where it was feasible. The inclusion of parallel questions on activity provides an independent check on the validity of the answers to the subjective questions. Answers to the question about the emphasis given to $\mathrm{R} \& \mathrm{D}$ can be compared to answers regarding the percentage of investment devoted to $\mathrm{R} \& \mathrm{D}$. Answers to the question about the emphasis given to training can be compared to answers regarding whether training is done. When these comparisons are made, it is almost invariably the case that the subjective valuation given by a firm to an activity and the probability that an action is undertaken are closely related.

Another potential problem arises in business surveys when respondents taken from different areas in a company have different views of the importance being given to different strategies. This is a particular problem when the views being solicited deal with prescriptive issues-what should be done (as opposed to a recollection of actual events), or what emphasis has been given in the past to these issues. Since The Survey of Operating and Financial Practices of Entrants focuses on the latter set of questions, the potential for this problem with the data is lessened. There is a second reason for arguing that this is a relatively unimportant problem with the survey. Although information loss in a large company may result in some senior personnel not fully appreciating the directions that the firm is taking, the survey being used here focuses on smaller firms, where all senior personnel are close to ongoing events. Since senior management usually filled in the survey, variability of responses across individuals is likely to be less of a problem.

Finally, there are other issues related to the nature of measurement that derive from an ordinal Likert scale. The measurement issue is handled here by using the extreme score measure (the percentage of firms scoring 4 and 5 on the five-point scale) to capture all firms that assessed themselves as higher than the median category. This gives a robust 
measure of the percentage of firms that felt they were above the midpoint of the distribution of scores that was given to them-but does not worry about distinctions above this point.

\subsection{Innovation Competencies}

As was previously described, innovation is not easily pigeonholed in one compartment. Some innovations involve new products; others involve new processes. Innovations will differ in terms of their novelty. In order to measure the diversity of innovative activity taking place, the stress that new small firms place on innovation is measured with 10 different variables. Each captures a different, though related, concept of innovation that is related to output.

The first set uses a question that asked whether an entrant had introduced an innovation and investigated the type of innovation. An innovation was defined as the introduction of a new or improved product or process; aesthetic changes that did not affect the technical construction or performance of the product were not included in the definition of an innovation. These innovations were, in turn, characterized as being either entirely new products, modifications of existing products, entirely new processes, or modifications of existing processes. Finally, entrants indicated whether these innovations were protected with intellectual property rights. Combinations of these measures are then used to define whether the entrants were introducing innovations of varying degrees of novelty and importance.

These variables are:

INGEN_-whether an entrant reports any innovation. This is the most inclusive category.

INIMP1-whether an entrant reports an innovation and it is protected by an intellectual property right such as a patent, or the firm reports that a strategy of protecting its innovations with intellectual property is important or very important (a score of 4 or 5). Baldwin (1997a) finds that the most novel innovations are those that tend to avail themselves of intellectual property protection. This is, however, the most restrictive definition of innovation-since patents are not suited to protecting all innovations, either because they are not easily described or because trade secrets and other forms of protection are more efficacious.

INIMP2-whether an entrant reports an innovation that is either a completely new product or a completely new process. This category is more restrictive than INGEN but does rely on self-reporting and, therefore, probably includes some innovations that would not be considered new by a panel of experts.

INPROD—whether an entrant is a product innovator. No qualification of novelty is made here. 
INPROC - whether an entrant is a process innovator. No qualification of novelty is made here.

INCOMP - whether an entrant is both a product and a process innovator. Small firms that are both product and process innovators have been found to be more successful than other innovators (Baldwin and Johnson, 1998).

To be innovative in accordance with the previous variables, a firm must have introduced an innovation in one of the three years prior to the survey. Since some firms may only introduce innovations over somewhat longer periods than three years, the use of this time period may miss firms that have an active research program but that have not succeeded in introducing an innovation in the time horizon chosen. Therefore, the variable set is extended to include variables that measure the emphasis that is given to a prime (though not the only) input to innovation-research and development. The variables that are used for this purpose are:

INRD—whether an entrant scored 4 or 5 on the importance given to R\&D capabilities.

INIMP - whether an entrant's percent of investment devoted to R\&D was above the median of all entrants that reported positive levels of R\&D expenditure.

Finally, the innovation tendencies are measured by the scores that are given to the importance that an entrant attributes to different competitive strategies that involve a broader concept of innovation. The SBA database on innovations includes a good percentage that involve modest rather than momentous improvements (Audretsch, 1995). Similar results are reported for the Netherlands (Kleinknecht, Reijnen and Smits; 1993) and for Austria (Fleissner, Hofkirchner and Pohl, 1993). Therefore, two variables were included that capture this broader concept. The first complements the earlier innovation measures by focusing on the importance given by the entrant to the frequency of introducing new products. By definition, a new product can involve minor product differentiation changes. The coverage of this variable is, therefore, broader than the variable derived from the question that asks whether there has been an innovation, since the latter involves an aspect of significance and importance that the new-product question does not. The variable used is:

INFREQ - whether an entrant scores 4 or 5 on the extent to which it frequently introduces new/improved products.

The second variable takes an even broader approach and examines the extent to which entrants focus on providing a different type of innovation-what might be referred to as the traditional innovation for smaller firms that involves customization and quality variation. The majority of small firms cannot compete directly on prices with larger firms because of the cost disadvantages associated with smaller size. Instead, they stress a niche strategy by varying the quality of product, offering slightly better levels of customer service, showing flexibility to customer needs or customizing their product for individual customer requirements (Baldwin et al., 1994). The value of a product to 
consumers is a function of its quality. All firms, but small firms in particular, are constantly experimenting with variations in quality to attract customers. These experiments all involve innovations - though, in most cases, they are incremental in nature. While incremental, their importance should not be discounted. The cumulative effect of the sum of many changes at the margin can be large. The variable used to catch this aspect of innovation is:

INTRAD_whether an entrant scores at least 18 out of a possible 20 points on the importance attributed to quality, customer service, flexibility in responding to customer needs and customization.

\subsection{Technological Competencies}

The second advanced competency focuses specifically on whether technological capabilities - the application of advanced technologies as opposed to general prowessin an entrant are important. As was the case for innovation, technological competency has more than one dimension and, as a consequence, is measured here in several different ways. Technological innovation involves a different though related dimension of innovation - the extent to which an entrant focuses on advanced technology. In the first instance, this is measured directly. These variables are meant to capture the wide variety of changes that occur in the production process that would not necessarily be captured by a simple question that asked whether process innovation is occurring. The variables used here are:

INTECH1-whether an entrant scores 4 or 5 on the importance attached to developing new and refining existing technology.

INTECH2-whether an entrant scores 4 or 5 on the importance attached to purchasing technology from other firms.

TEDEV — whether an entrant both develops/refines new technology and purchases it.

The first three variables capture a generalized concept-that of technological competence. Since some firms may respond better to a more precise formulation of their skills, four additional variables were included. The first three ask whether computers are used in process control, whether information technology is important, and whether a large percentage of investment goes for technology acquisition.

TECOMP-whether an entrant scores 4 or 5 on the importance given to using computercontrolled processes in production. This emphasis was found previously (Baldwin et al., 1994) to be closely related to measures of a firm's success.

TEINFO-whether an entrant scores 4 or 5 on using information technology for management purposes. Information technologies are perhaps one of the most important of the advanced technologies being incorporated into the production process. Manufacturing firms that have successfully incorporated information technology have been found to be 
improving their productivity and market share relative to those who were not (Baldwin, Diverty and Sabourin, 1995).

TEINP - whether an entrant's percent of investment devoted to technology acquisition was above the median of all entrants that reported positive levels of investment devoted to technology acquisition.

Finally, an all inclusive technology variable is included to capture an aspect of production technology that is commonly emphasized by many firms and whose success depends in one way or another on the technology in place in a firm. This variable is:

PROD1-whether an entrant scores 4 or 5 on improving efficiency of input use in the production process and on reducing production times.

\subsection{Human Capital Development}

The final set of competencies considered here are worker skills. Entrants incorporate these skills either by focusing their human-resource strategies on hiring skilled workers or by developing these skills themselves through training programs. In both cases, a firm's innovation competencies are facilitated by the amount of human capital that it possesses. Baldwin and Johnson (1996) report that a human-capital strategy is pursued more intensely by innovators in both the goods and the services sectors. Baldwin, Gray and Johnson (1997) establish the close connection between the adoption of advanced manufacturing technologies and a firm's emphasis on training. In the goods sector, an emphasis on training is often combined with an emphasis on R\&D or the development of new machinery and equipment. In the services sector, the innovation strategy often is the human-resource strategy.

The emphasis on human capital is measured here by the value that an entrant attaches to recruiting skilled labour, by the emphasis it gives to training, and finally by the extent to which it implements a formal training program and invests in training. The variables are:

LABSKL-whether an entrant scores 4 or 5 on the importance given to recruiting skilled employees.

LABSCOR—whether an entrant scores 4 or 5 on the importance attached to training.

LABFOR—whether an entrant does formal training.

LABTRAIN—whether an entrant's share of investment devoted to training is positive.

LABINT - whether the percentage of investment that is devoted to training is above the median for all entrants that have positive levels of investment in training. 


\subsection{Incidence of Innovation, Technological Competencies, and Focus on Skills in the Entrant Population}

Most entrants are innovative in one or other of the ways outlined above, but the percentage of the population of entrants that are innovative differs considerably depending upon which of the summary measures is used. This is illustrated in Figure 3.6.1.

Figure 3.6.1

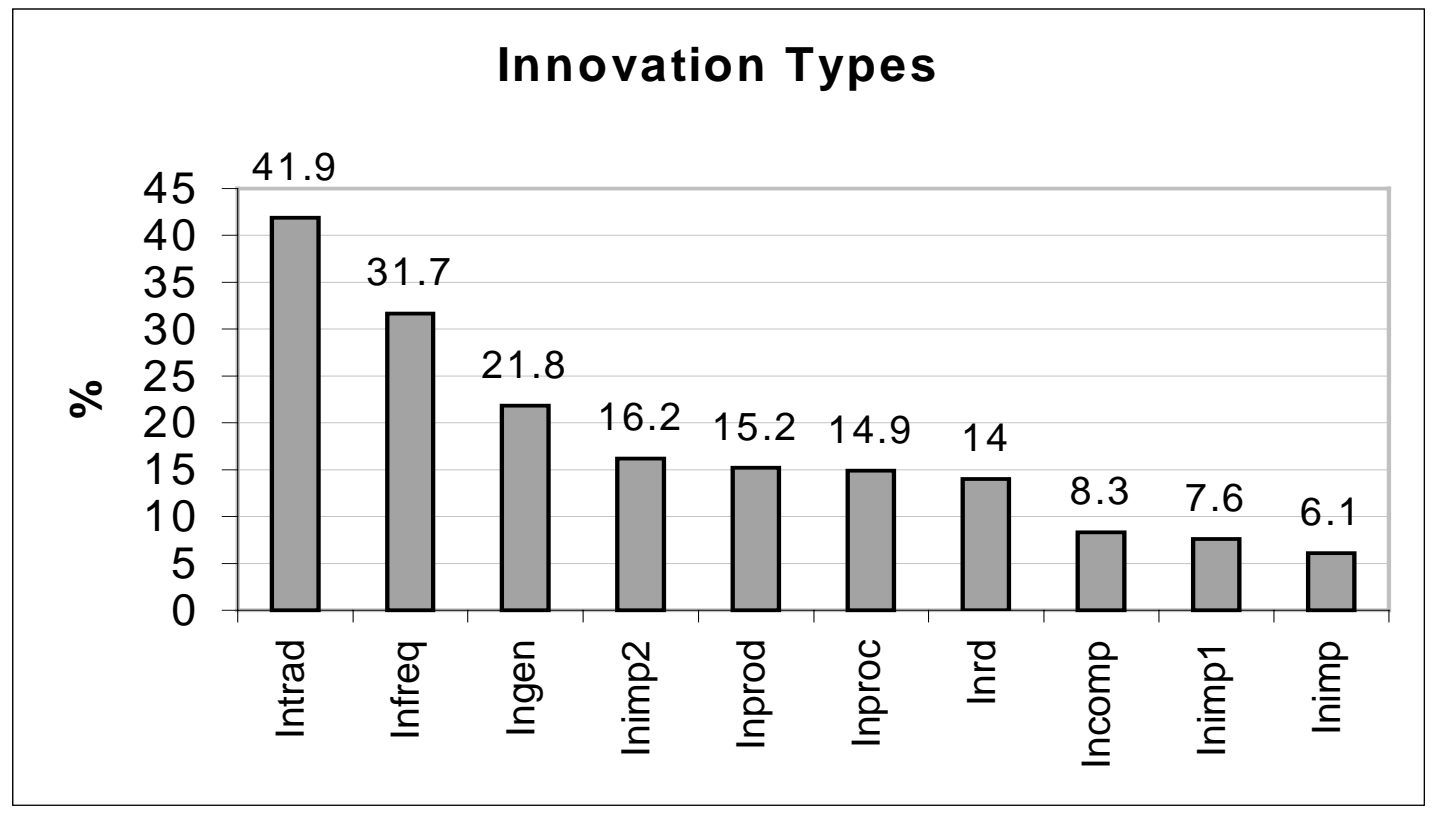

Many firms are experimenting with the type of innovation that requires bundling service or quality with a good. About $42 \%$ of the population place a heavy emphasis on varying quality to provide a unique product to the consumer (INTRAD). Somewhat fewer are introducing new products. Some $32 \%$ place more than average importance on frequently introducing new products (INFREQ). When 'new' is interpreted to mean an 'innovation', fewer firms fall into this category. Some $22 \%$ have introduced an innovation over the 1992-94 period (INGEN). Some 14\% of entrants emphasized an R\&D strategy (INRD) but some $29 \%$ either report an innovation or that they place above average importance on $\mathrm{R} \& \mathrm{D}$ - about the same percentage that emphasize the frequent introduction of new products.

When the constraint of genuine novelty is imposed on the innovation, the percentage declines by amounts that vary depending on the definition of novelty. Only $16 \%$ introduced what they consider to be an entirely new product or process (INIMP2). Some $8 \%$ introduced an innovation that was protected by formal intellectual property rights (INIMP1). Despite these differences, it should be noted that the vast majority of entrants are innovative by one or other of these standards: roughly $70 \%$ of all firms fall into one of the categories defined here. Innovation is an activity that is widely pursued. 
The various measures of the firm's technological capabilities indicate a diversity of technological competencies. These are examined in Figure 3.6.2.

\section{Figure 3.6.2}

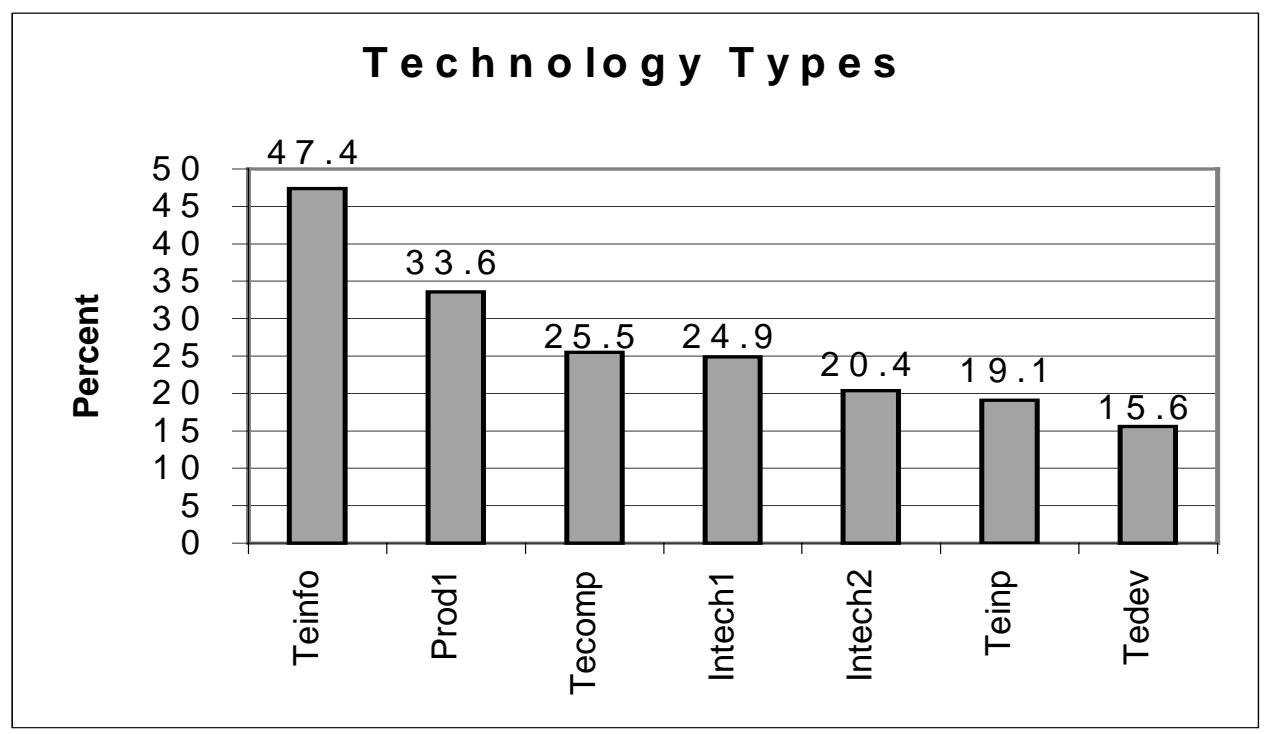

In accord with the finding of Baldwin and Sabourin (1995) that communications technologies have been expanding fastest, the largest group of firms (47\%) emphasize the importance of computer-based information technologies (TEINFO). The next largest percentage of entrants (34\%) focus on methods to reduce the cost of inputs and to reduce production times (PROD1). Roughly $25 \%$ place heavy emphasis on developing new technologies (INTECH1) or use computer-controlled processes in production (TECOMP). There are about 20\% who stress the purchase of new technologies (INTECH2). Finally, 16\% of firms both develop new technologies and purchase new technologies from others (TEDEV). Once again, a clear majority of entrants are engaged in some form of technovation; here too approximately $70 \%$ fall into at least one of the technovation categories.

There is also a large percentage of firms who stress the importance of worker skills and training. This is examined in Figure 3.6.3.

Roughly 56\% indicate that training is important (LABSCOR) and devote considerable importance to recruiting skilled labour (LABSKL). About the same percentage perform formal training to upgrade their employees skills (LABFOR). Some 52\% have implemented a formal training program. Even if we judge whether firms are performing substantial activity in this area-on the basis of whether they report that they devote part of their investment to training (LABTRAIN) - 31\% of new firms still are seen to be serious participants in upgrading human capital. Thus, a large percentage of entrants are part of the knowledge economy in the sense that they place a high value on human capital. 
Figure 3.6.3

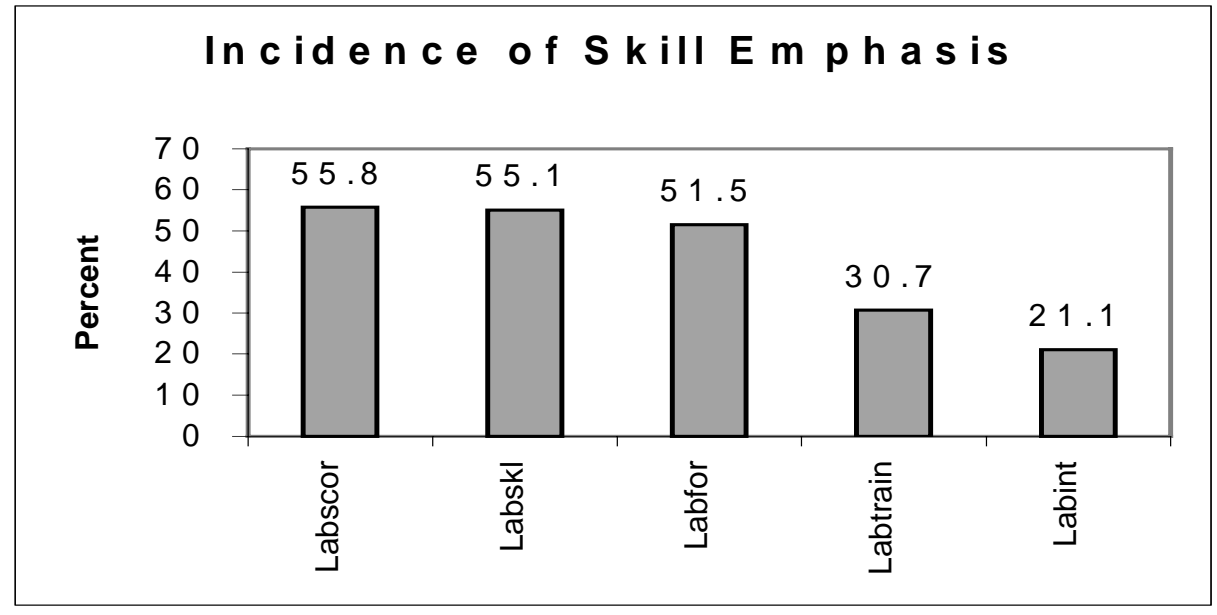

These data show that a substantial proportion of new entrants consider themselves to be either innovative or technologically advanced or to depend on skilled workers. When we consider the characteristics jointly, the percentage of entrants that fall into at least one category increases. For example, $22 \%$ of new firms report an innovation, $14 \%$ place a very high importance on R\&D and $29 \%$ report at least one of these two characteristics. Similarly, $25 \%$ of entrants report that they develop new or refine existing technology, while $20 \%$ bring in outside technology; but some $30 \%$ perform at least one of these two. Some $47 \%$ of entrants use information technology in management and $25 \%$ use computers for process control, however, 53\% of entrants exhibit at least one of these characteristics. When we expand our definitions of innovation to encompass a characteristic from more than just the innovative group, the percentage of entrants that can be said to be innovative is quite large. Some 39\% report an innovation, or perform R\&D, or emphasize either the development or purchase of technology. Some $65 \%$ report one of the above competencies, or emphasize computer-controlled processes, or stress the use of information technologies.

\section{An Industry Taxonomy}

The previous section examined the incidence of advanced innovation, technology, and skill-based competencies within the entrant population. These data, in turn, can also be used to classify industries on the basis of their technological prowess. With this in mind, the current section has several objectives. We first use the above data to derive competency-based indices for each dimension of technological prowess under studyone for innovation, technological use, and human capital, respectively. These indices are then combined in order to construct our multidimensional measure of advanced competency. We then use these indices to explore differences in the identification of high-tech and low-tech industries. In doing so, we ask whether the innovation, technology, and human skill indices provide the same information-that is, do they rank industries identically? Our goal is to ascertain whether there is one simple classification that more or less captures the various aspects of technological prowess that many 
observers have associated with the new knowledge economy. Finally, we use each of these indices to investigate the incidence of high-tech firms in high-tech and low-tech industries.

\subsection{Devising Firm-based Indices}

In order to examine how industries differ across the dimensions that our survey measures, the respondents' scores on each of the measured characteristics were averaged at the industry level for a set of 48 industries in order to produce three indices-one for innovation (INAV), one for skill-based competencies (LABAV), one for technology (TEAV). Each index, by construction, yields the percent of firms that can be considered as advanced-either in terms of innovation, technology, or skill development.

The industries used for this analysis consist of combinations of the standard three-digit classifications. The combinations chosen depend, in the first instance, on the availability of sufficient observations on respondents to yield meaningful estimates for the industry. Second, where possible, an industry segment was split into those where R\&D is important and those where it is not. ${ }^{14}$ The industries are listed in Appendix A.

The indices-INAV, LABAV, and TEAV-were created by averaging a related set of variables. Not all firms stress each of the aspects of innovation, technovation, and skills that are included in each measure-but they are related. Correlation analysis is used to depict the relationship between the variables that are included in each index. The correlations of the industries' scores calculated for each of the major innovation variables are presented in Table 4.1.1.

Table 4.1.1. Correlation of Innovation Variables

\begin{tabular}{|l|c|c|c|c|c|c|c|c|}
\hline & \multicolumn{8}{|c|}{ INNOVATION COMPONENTS } \\
\cline { 2 - 9 } & INGEN & INFREQ & INIMP & INIMP1 & INIMP2 & INPROC & INPROD & INRD \\
\hline INFREQ & .58 & & & & & & & \\
INIMP & .57 & .54 & & & & & & \\
INIMP1 & .77 & .62 & .44 & & & & & \\
INIMP2 & .84 & .54 & .70 & .49 & & & & \\
INPROC & .82 & .39 & .29 & .71 & .47 & & & \\
INPROD & .86 & .67 & .67 & .78 & .81 & .54 & & \\
INRD & .85 & .61 & .54 & .88 & .64 & .75 & .81 & \\
INTRAD & .44 & .54 & .45 & .19 & .58 & .47 & .81 & .31 \\
\hline
\end{tabular}

Most of the innovation variables are highly correlated, but not perfectly. There are relatively high correlations between the innovation percentage (INGEN) and the percentage where new innovations are important (INIMP2) or where R\&D is important (INRD). The latter is also closely correlated with the variable that measures whether an industry innovates and uses intellectual property (INIMP1). Industries with process innovations (INPROC) and those with product innovations (INPROD) are only

${ }^{14}$ See Baldwin and Rafiquzzaman (1994) for a discussion of this classification. 
imperfectly correlated (.54). This serves to emphasize the point made earlier that industries producing new products are not the same as those focusing on new processes. The percentage of firms in an industry that report intense R\&D expenditure (INIMP) is more highly correlated with product innovation (INPROD) than process innovation (INPROC).

The innovation index is generated in the first instance by taking the average of the variables that are generally regarded as being closely associated with innovation (INGEN, INPROC, INPROD), important innovation (INIMP1, INIMP2), with the importance of investment in $R \& D$ (INIMP), and the importance attributed to $R \& D$ (INRD). We then had to decide whether to include the two more inclusive variablesINFREQ and INTRAD. The latter are clearly neither completely different nor completely the same as the percentage of firms reporting an innovation. The percentage of firms responsible for innovations (INGEN) has a correlation of .58 with the percentage of firms introducing new products (INFREQ). The percentage with innovations (INGEN) has only a correlation of .44 with the percentage that are innovative in the traditional sense (INTRAD).

To test the sensitivity of the ranking scheme to the inclusion of the latter two more expansive definitions of innovation, three averages were created (INAV1, INAV2, and INAV3). The first (INAV1) includes only the core innovation variables. The second (INAV2) adds to INAV1 the percentage of firms introducing new products (INFREQ). The third (INAV3) adds the percentage of firms stressing the traditional service, quality dimensions. Industries were ranked by INAV1 and the three values of the index are plotted in Figure 4.1.1.

\section{Figure 4.1.1}

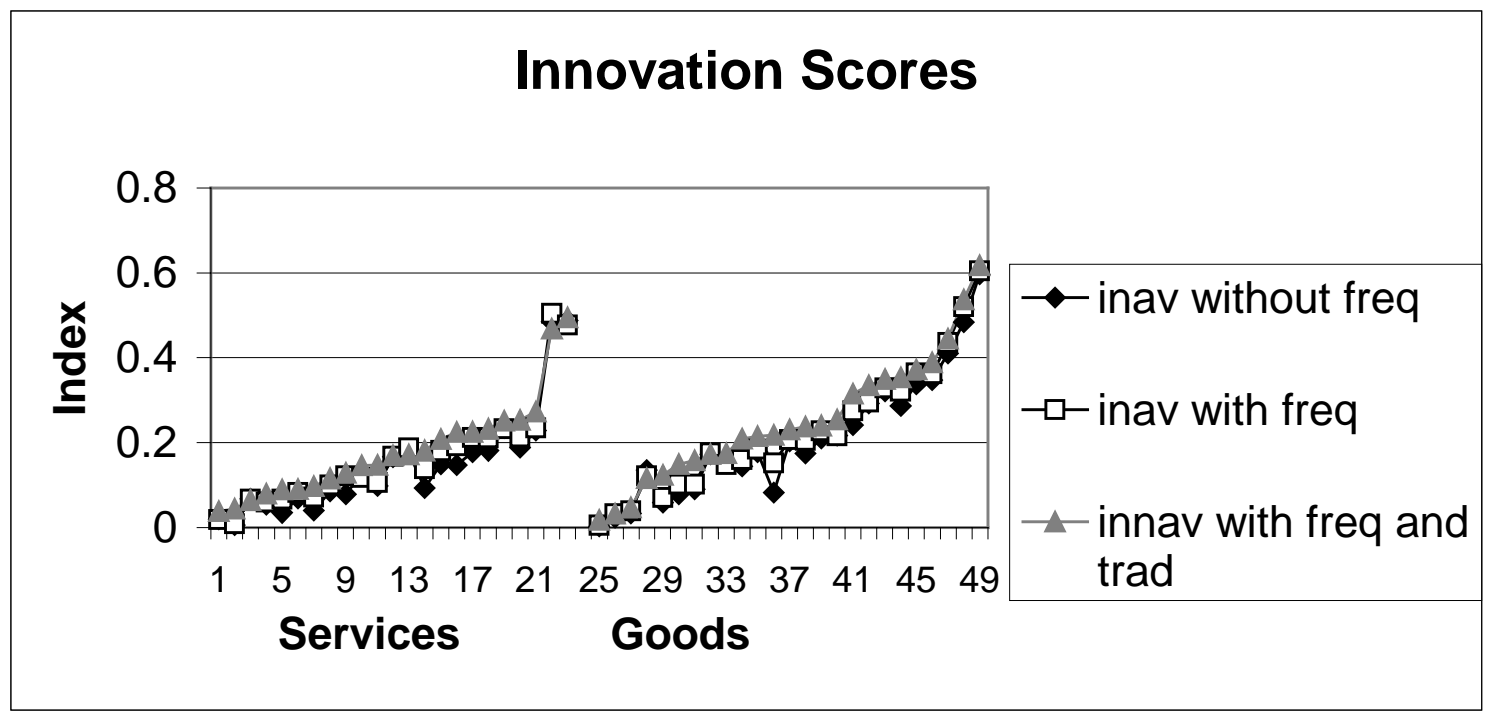


The three innovation-based indices rank the industries in a similar fashion. INAV1 has a correlation of .99 with INAV2 and .98 with INAV3. Since there is little difference in the industry ranking provided by the three indices, we arbitrarily choose the intermediate index with INFREQ included.

Table 4.1.2. Correlation of Technology Components

\begin{tabular}{|l|r|r|r|r|r|r|r|}
\hline & \multicolumn{7}{|c|}{ TECHNOLOGY COMPONENTS } \\
\cline { 2 - 9 } & PROD1 & INTECH1 & INTECH2 & TECOMP & TEDEV & TEINFO & TEINP \\
\hline INTECH1 & .66 & & & & & & \\
INTECH2 & .18 & .64 & & & & & \\
TECOMP & .31 & .64 & .47 & & & & \\
TEDEV & .20 & .68 & .94 & .45 & & & \\
TEINFO & .22 & .26 & .16 & .60 & .63 & & \\
TEINP & .05 & .21 & .32 & .33 & .32 & .38 & \\
INPROC & .30 & .63 & .62 & .71 & .62 & .17 & .17 \\
\hline
\end{tabular}

We next turn to examine technovation measures. In the first instance, the technology index consisted of INTECH1, INTECH2, TECOMP, TEDEV, TEINFO and TINP. The first two competencies have a correlation of .66 (Table 4.1.2). Thus, industries that develop new technologies (INTECH1) are also those that are more likely to purchase new technologies (INTECH2). Technological sophistication in terms of developing new technologies (INTECH1 or INTECH2) is more closely related to the use of computerprocess technologies (TECOMP) than to the use of information technologies to aid management (TEINFO). The correlations with the intensity of process innovators (INPROC) are also included in the table, since this is an alternate variable that could be used to measure the technological prowess of an industry. It is not included here in the technology index because it is already included in the innovation index. It is more closely related to INTECH1, INTECH2, TECOMP, and TEDEV than to either TEINFO, TEINP, or PROD1. The most commonly emphasized strategy—input cost reducing (PROD1) has a relatively low correlation with all the others.

To test the sensitivity of the ranking scheme to the inclusion of the more expansive variable (PROD1), two averages were created (TECHAV1 and TECHAV2). The first includes only the core technology variables. The second (TECHAV2) adds to TECHAV1 the percentage of firms focusing on a cost-reducing input strategy (PROD1). The industries were ranked by TECHAV2 and the value of each index is plotted in Figure 4.1.2.

The two indices rank the industries in a similar fashion. The correlations are .97 for services and .98 for goods. In what follows, we choose the more inclusive definition that includes PROD1. 
Figure 4.1.2

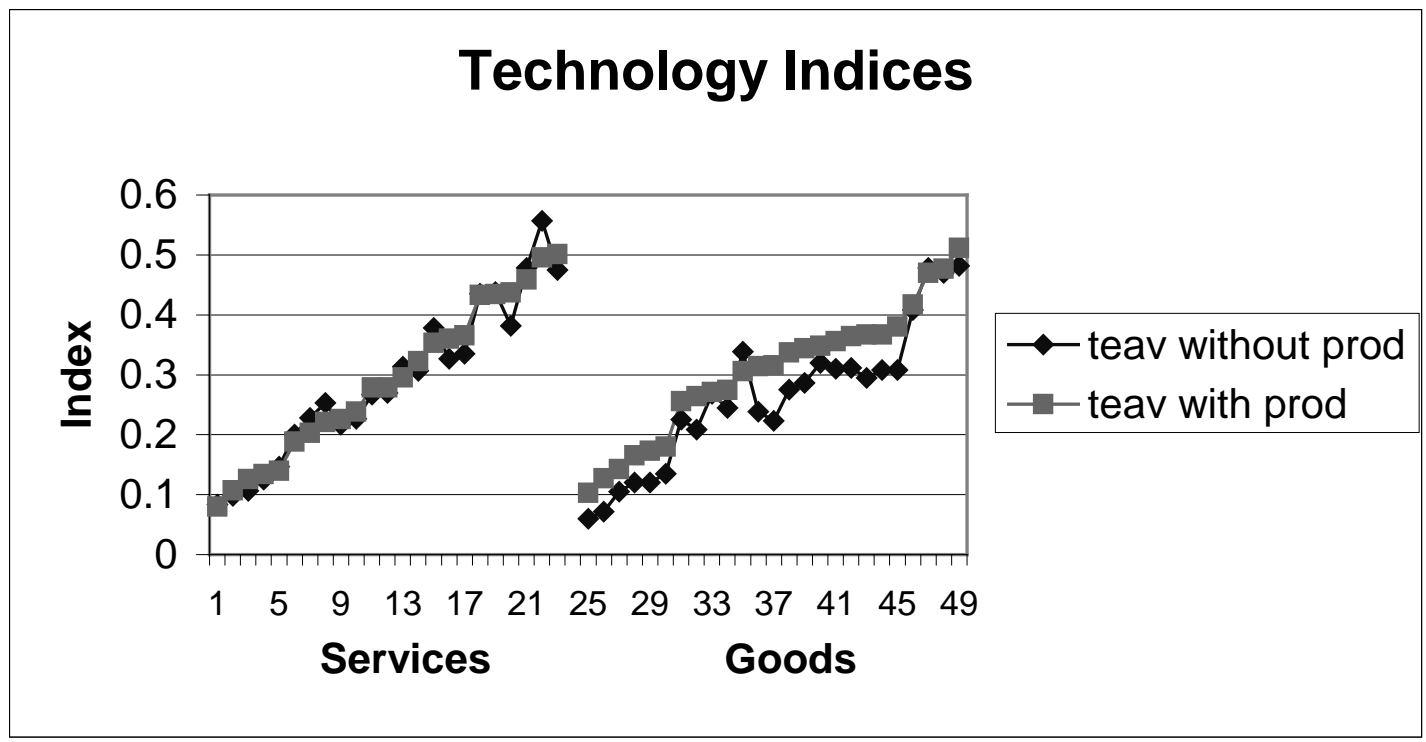

Finally, we turn to examine skill-based competencies. The skill-related index consists of LABFOR, LABINT, LABSCOR, LABSKL AND LABTRAIN. It is plotted in Figure 4.1.3.

Table 4.1.3. Correlation of Knowledge Variables

\begin{tabular}{|l|c|c|c|c|}
\hline \multirow{2}{*}{} & \multicolumn{4}{|c|}{ KNOWLEDGE COMPONENTS } \\
\cline { 2 - 5 } & LABFOR & LABINT & LABTRAIN & LABSCOR \\
\hline LABINT & .64 & & & \\
LABTRAIN & .75 & .80 & .48 & \\
LABSCOR & .62 & .37 & .52 & .81 \\
LABSKL & .60 & .40 & \\
\hline
\end{tabular}

The cross-industry correlations between the skill-related components are also highthough here too, there are indications that there are different dimensions to knowledge. The variable measuring the percentage of firms in an industry performing formal training (LABFOR) has a correlation of .64 (Table 4.1.3) with the variable measuring the percentage of firms with any investment devoted to training (LABTRAIN) and .75 with the percentage that have a large share of investment devoted to training (LABINT). However, not all industries where firms emphasize the importance of having skilled employees (LABSKL) spend large percentages of their budget on training (LABTRAIN), since the correlation is only .52 between these variables. Industries can develop a strong human capital base by recruiting and/or training. Not all industries do both-because in some cases, the skills required will not be available through the educational system. 
Figure 4.1.3

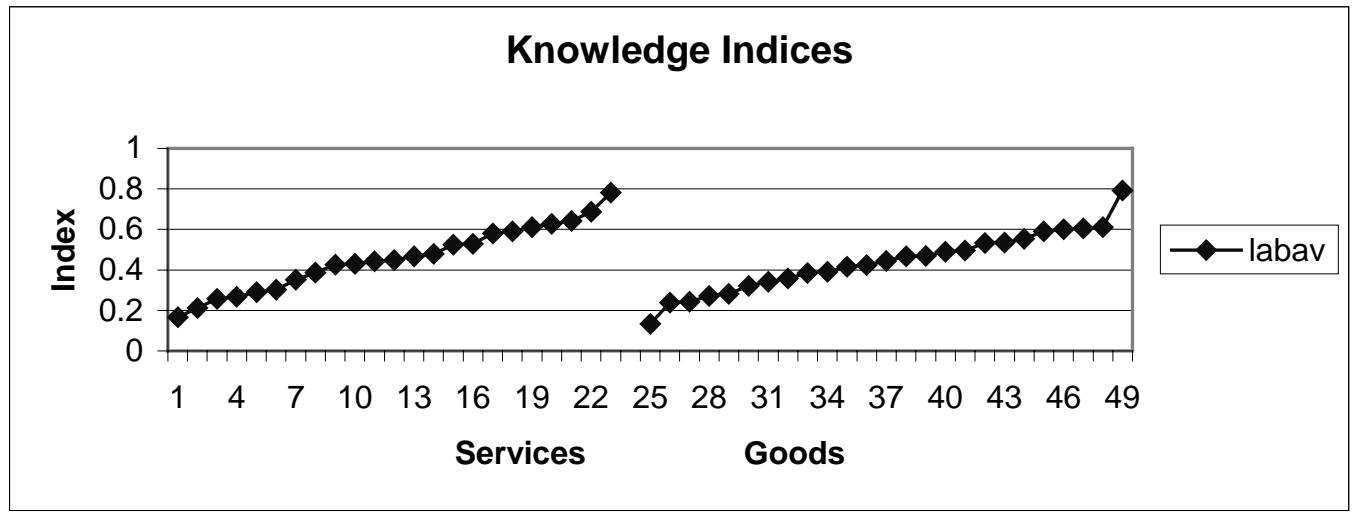

Each of the three indices developed here-innovation (INAV), technology (TEAV), and skill (LABAV) - ranks industries more or less continuously from those with the lowest to the highest scores. ${ }^{15}$ Moreover, the three measures capture similar though not identical dimensions of advanced competencies. Table 4.1 .4 reports the correlation coefficients for the various indices.

Table 4.1.4. Correlation of the Three Competency-Based Indices

\begin{tabular}{|l|c|c|c|c|c|c|}
\hline \multirow{2}{*}{} & \multicolumn{5}{|c|}{ AVERAGE CHARACTERISTICS } \\
\cline { 2 - 7 } & ALL & SERVICES & GOODS & ALL & SERVICES & GOODS \\
\cline { 2 - 7 } & .55 & .60 & .58 & & & \\
\hline SKILLS & .62 & .47 & .76 & .57 & .46 & .66 \\
TECHNOLOGY & .62 &
\end{tabular}

The correlation between the industry scores on the innovation index and the skills index is .55 , while it is .62 between the innovation and technology index for all industries. The correlation between skills and innovation is about the same in both the goods and services sectors, but the relationship between technology and innovation or between technology and skills is higher in the goods sector than in the services sector.

\subsection{Industry Differences Using the Competency Approach}

In order to further assess the relation between indices and ultimately to compare the ranking given by our index that is derived from firm-based competencies to rankings produced by other indices, we created an overall index by averaging the individual innovation, skills, and technology indices. To investigate the extent to which the innovation, technology and skills indices yield comparable rankings, we ranked all industries by the overall index and plotted each of the individual components. This is done for goods industries in Figure 4.2.1 and for service industries in Figure 4.2.2. By

\footnotetext{
${ }^{15}$ Compared to the R\&D type index reported in Figure 2.1.1, which bunches most industries into a small range.
} 
Figure 4.2.1

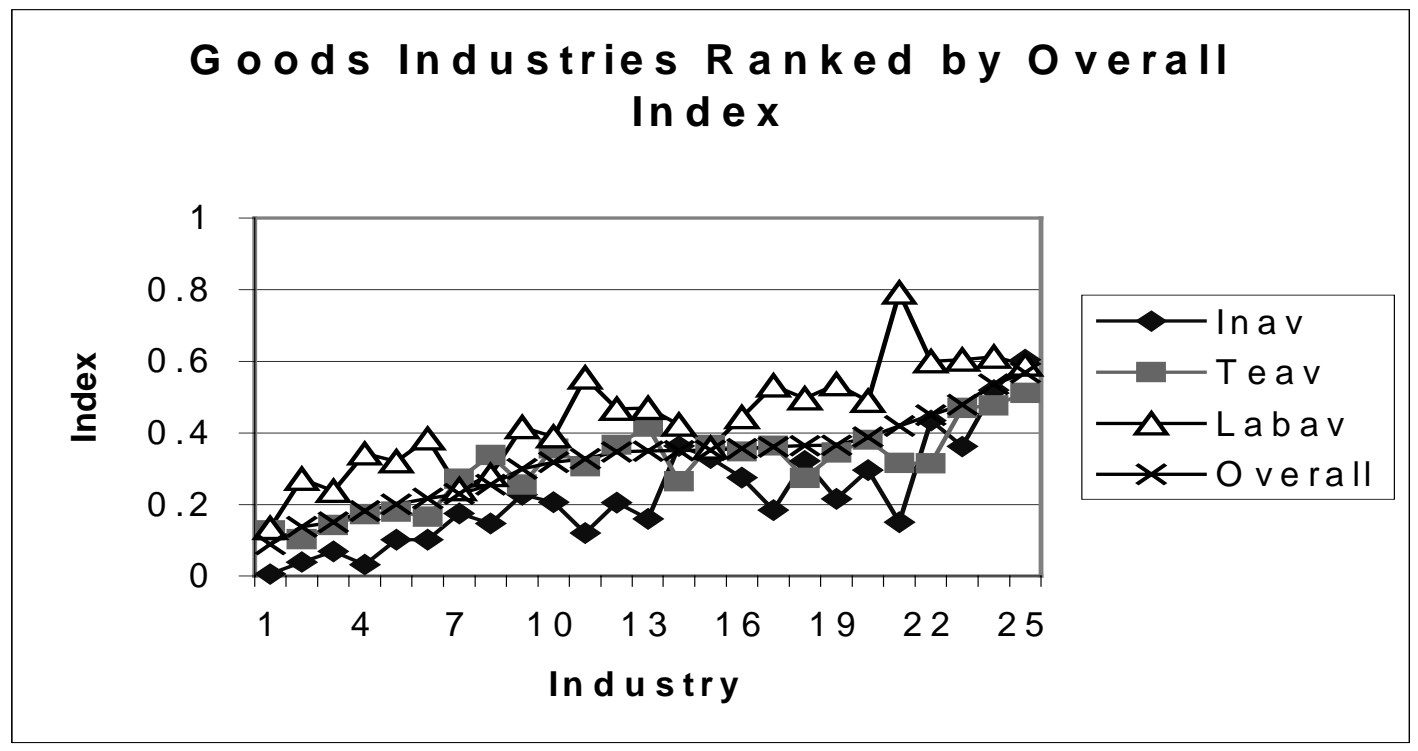

construction, the index measures the percent of firms that are advanced in an industry, where innovation, technology, and skill development are considered.

For the goods sector, the skill and the innovation indices (LABAV \& INAV) track the overall index, at least in the sense that dividing the sample at the median on the basis of the overall index would also divide the sample into industries that generally have the highest and lowest values of the innovation and skills indices. ${ }^{16}$ This does not occur for the technology index (TEAV). In the goods sector, there are a number of industries that are in the bottom half of the distribution when classified by the overall index, but that possess values of the technology index that are at least as high as many in the top half. This suggests that the technology index has several dimensions that are different from the innovation and human-capital variables. New firms can consider themselves among the most technologically advanced without reporting that they are among the most innovative or that they place the heaviest emphasis on skilled workers. This highlights the need to utilize more than one dimension to measure the advanced competencies of industries.

In the services sector, the technology index (TEAV) tracks the overall index quite well, but the innovation index (INAV) does less well. Here there are a number of industries that are classified to the top half of the distribution on the basis of the overall index, whose innovation value is not greatly different than for industries in the bottom half. There is also considerably more variability in the skills index (LABAV) in the services sector than in the goods sector.

\footnotetext{
${ }^{16}$ We focus on this criterion since it is a similar dichotomous division that is used when others divide their sample into high-tech and low-tech sectors.
} 
Figure 4.2.2

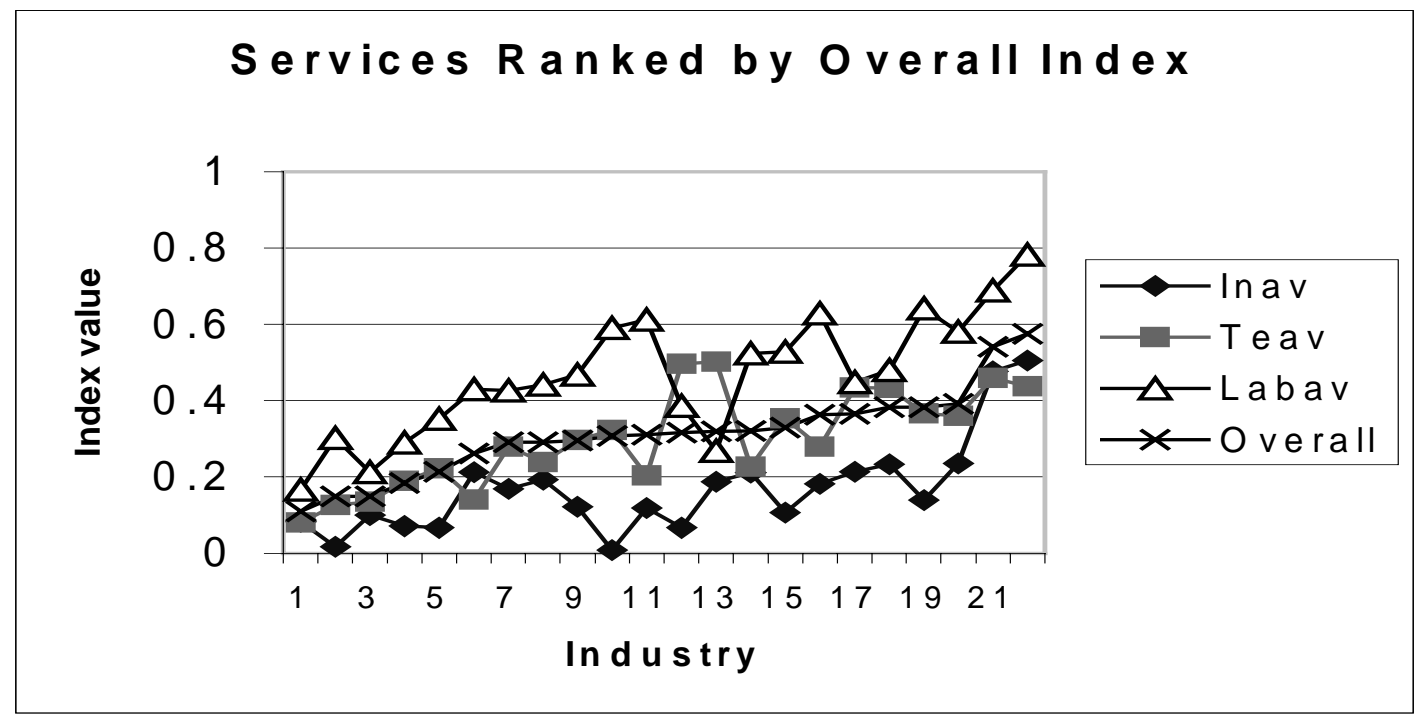

The differences in relationships between the goods and services sectors suggest that classification of industries into high- and low-tech using one dimension is more problematic in the latter than in the former.

\subsection{The Location of High-Tech Firms}

While taxonomies are often utilized for the purpose of classifying industries as high- as opposed to low-tech, low-tech industries should not be considered to be devoid of technically advanced firms, nor, for that matter, should high-tech sectors be viewed as consisting entirely of high-tech firms. To demonstrate this, we separated both the goods and services industries into high- and low-tech sectors based on each of our indices outlined in sections 4.1 and 4.2. For a given index, industries with scores above the median were classified as high-tech, whereas those with scores below the median were deemed low-tech. Table 4.3.1 reports the average value of the indices for the high- and low-tech sectors, respectively.

Table 4.3.1. Average Index Values for Firms in High- and Low-tech Sectors (\%)

\begin{tabular}{|l|c|c|c|c|}
\hline & Innovation & Technology Index & Skill-based Index & Overall Index \\
\hline High-tech (goods) & 31 & 39 & 56 & 41 \\
Low-tech (goods) & 9 & 21 & 32 & 23 \\
\hline High-tech (services) & 25 & 39 & 58 & 40 \\
Low-tech (services) & 7 & 18 & 32 & 23 \\
\hline
\end{tabular}


For service industries classified to the low-tech sector, the average score for the technology index is $18 \%$. For the high-tech sector, the index value stands at $39 \%$. That is, the low-tech services sector contains about half as many firms (18\%) that excel in technological competencies as the high-tech services sector (39\%). We find a comparable relation in terms of goods industries with low- and high-tech scores of $21 \%$ and $39 \%$, respectively. When the skills-based index is used, the percentage of high-knowledge firms in low-tech industries is more than half those in high-tech industries (i.e. $32 \%$ and $56 \%$ for goods, $32 \%$ and $58 \%$ for services, respectively). By contrast, when the innovation index is used, there are relatively fewer high-innovation firms in low-tech industries for both the goods and services sectors. In summary, industries that might be classified as low-tech on the basis of these indices are not devoid of firms with advanced competencies. Nor are industries that might be classified as high-tech comprised exclusively of firms that exhibit these competencies. When the three indices are averaged to create an overall index, industries that are ranked in the low-tech sector contain at least half as many high-tech firms as industries that are ranked in the high-tech sector.

\section{A Comparison of Firm-Based and Other Industry-Based Classification Schemes}

The advantages of the survey-based indices derived in the previous sector are twofold. First, they capture in a rich fashion the dimensions related to commonly accepted firm characteristics that are associated with technological prowess. They deal with innovation, with skills and training, and with technological capabilities. They also are derived from small, new firms - a population that is believed to be spearheading change and to be at the forefront of innovation as they develop new products at the beginning of their product life cycle.

Second, we focus directly on new technology-based firms rather than on large incumbent firms to derive a classification scheme. Studies that examine the characteristics of new high-tech firms require taxonomies based on these firms rather than just on large firms. Aggregate industry characteristics-such as R\&D intensity-are derived from the population of all firms. Since firm sizes are skewed, aggregate industry characteristics are heavily influenced by the values of the largest firms. An industry may have a high R\&Dto-sales ratio because one large firm is R\&D intensive, while most of the small firms may perform little R\&D. In other cases, larger firms may not be $R \& D$ intensive, while new small firms may perform considerable $R \& D$. It is inappropriate to use an aggregate index to classify the environment in which small, new firms operate when small firms possess characteristics that are quite different from large firms. Since small firms often have to adopt a niche strategy in order to survive, they often look quite different from large firms (Cooper, Willard and Woo, 1986).

To examine this issue, we compared the ranking produced by the competency-based indices to the rankings given by several alternatives that are based on aggregate industry characteristics. We generated the first alternative ourselves from aggregate industry characteristics to capture the 'knowledge' components of industries. Several variables were used to classify goods industries. First, the percent of sales devoted to R\&D was 
used to replicate the emphasis on R\&D found in the OECD high-tech classification system. Second, the percent of firms using advanced technologies was used to capture the technological bent of the industry. Third, the industry's tendency to be innovative was measured using the Robson classification scheme that divides industries into a core, a secondary, and an 'other' sector. Fourth, the industry's average wage rate was included to capture the knowledge base of the industry. Fifth, the value of the industry's multifactor productivity measure was included since it captures the extent to which knowledge that is not imbedded in labour or capital is important for productivity growth.

These variables were then combined into an index using principal component analysis. Principal component analysis is a multivariate technique that is used to summarize the underlying dimensionality in a database. Principal component analysis derives a small number of linear combinations of the original variables that retain as much of the information in the original set as possible. As such it reduces the number of original variables to a more manageable set that captures the essence of the original set. This technique is used here to create one index that can be used to rank the various industries by their level of knowledge intensity. Principal component analysis of a set of industry characteristics $\left(c_{i}\right)$ finds new variables $\left(\mathrm{R}_{\mathrm{I}}\right.$ - the components):

$\mathrm{R}_{\mathrm{i}}=\mathrm{w}_{\mathrm{i} 1} * \mathrm{c}_{1}+\mathrm{w}_{\mathrm{i} 2} * \mathrm{c}_{2}+\ldots \ldots \ldots \ldots \mathrm{w}_{\mathrm{in}} * \mathrm{c}_{\mathrm{n}}$, where $\mathrm{w}_{\mathrm{i}}$ are the weights and $\mathrm{c}_{\mathrm{i}}$ are the original variables.

The variables $\mathrm{R}_{\mathrm{i}}$ exhaust the variance in the original set and are orthogonal to one another. The first component is chosen to maximize the proportion of the total sample variance for which it accounts. The next component is chosen to be orthogonal to the first and to maximize the remaining variance. We use the first principal component to capture that measure of the underlying industry characteristics that is most important-in the sense that it exhausts the largest part of the underlying variation in the data set.

The weights $\left(\mathrm{w}_{\mathrm{i}}\right)$ can be used to interpret the meaning of the component. For example, a high positive weight on an innovation variable such as $\mathrm{R} \& \mathrm{D}$, but a low one on skills, means the component represents those firms that perform $R \& D$ but do not do much training.

The weights are reported in Table 5.1 for the first principal component of the goods industries. The value of the first principal component was used to divide the industries into two groups. The top half were defined as being high-knowledge, the bottom half were deemed to be low-knowledge.

Table 5.1. Variables and Associated Weights for the Goods Producing Knowledge Index

\begin{tabular}{|l|c|}
\hline \multicolumn{1}{|c|}{ Variables included in the index } & Weight in Index \\
\hline Multifactor Productivity Measure & 0.042 \\
Proportion of Workers with Post-Secondary Education & 0.519 \\
Score on Innovation Index & 0.538 \\
Percent of Sales Devoted to R\&D & 0.474 \\
Percent of Firms Using Advanced Technologies & 0.464 \\
\hline
\end{tabular}


A similar procedure was employed for services industries-except here there are fewer meaningful variables that can be generated at the industry level. The variables used were GDP per hour worked, the proportion of workers with post-secondary education, and the average wage rate. Table 5.2 contains the weights provided by the principal component analysis for the services industries. The value of the first principal component was used to divide the services industries into high- and low-knowledge groups.

Table 5.2. Variables and Associated Weights for the Services Sector Knowledge Index

GDP per hour worked in 1992

Variables included in the index

Proportion of Workers with Post-Secondary Education

Average Wage Rate

Weight in Index
0.516
0.562
0.647

The high-low knowledge classification using the aggregate approach was then compared to the overall firm-based classification generated by the survey. For this purpose, the aggregate index was used to divide the universe of three-digit industries at the median. This classification was then applied to our sample giving us a number $\left(\mathrm{n}_{1}\right)$ of high-tech and $\mathrm{n}_{2}$ of low-tech industries. We then chose the same number of high-tech industries and low-tech industries using our overall index to rank our sample from top to bottom. In both cases, a binary variable was created that assigned a 0 to a high-tech industry and a 1 to a low-tech industry.

We first compared the two by correlating the 0/1 binary variable for each classification. Correlations between the two classification schemes are reported in Table 5.3.

Table 5.3. Correlations of Survey-Based Index to Indirect Measures

\begin{tabular}{|l|c|}
\hline & Overall Survey Index \\
\hline Aggregate Index & .07 \\
Goods Sector & .24 \\
Services Sector & -.08 \\
\hline
\end{tabular}

Note: construction assigned to services

For goods and services industries combined, the correlation was only .07. The aggregate industry-based index has a higher correlation with the goods sector (.24) than with the services sector (-.08). Indeed the latter is negatively correlated with the entrant-based competency index. We also examined whether this pattern differed across the subcomponents of the overall index - the innovation, skill, technology sub-indices-to see if any of these components might be more closely related to the aggregate index. None were. In conclusion, the aggregate knowledge-based index that we constructed is not closely related to new-firm competencies in the area of innovation, knowledge, or technology.

In addition to correlation analysis, we compared the two classifications by asking how many industries are classified identically under the two schemes. For the goods sector, only $52 \%$ industries are correctly classified. For the services sector, only $48 \%$ are 
correctly classified. Finally, we performed a chi-squared test and concluded that the two classification systems were independent of one another.

This comparison relies on an index of firm-based characteristics derived from a survey that is the simple sum of the innovation, knowledge, and technology sub-components-a procedure that weights all variables equally. Alternately, we performed a principal component analysis on our competency variables to create a second entrant-based overall index-using the first principal component. This component has the highest weights on the general innovation variable (INGEN), on the important innovations variable (INIMP2), on the developing technology variable (INTECH1), on purchasing technology (INTECH2), and on training labour (LABTRAIN, LABFOR). ${ }^{17}$ This component then captures aspects of all three competency-based indices. When we compare the high/low categorization of industries based on industry scores using this component to that derived from aggregate industry characteristics described previously, the correlation is found to be no better than those reported above. The use of the key component derived from our firm-based measures to rank industries does not change our conclusion that a rich and varied set of small-firm characteristics - as revealed by the firms themselves-show a different pattern than aggregate industry characteristics derived from R\&D-to-sales ratios, average wages, and technology use.

To further investigate the adequacy of aggregate indices, we compared the results using our firm-based index to the results derived from using an aggregate measure developed by Lee and Haas (1996) that divides industries into 'high-knowledge' and 'lowknowledge' groups on the basis of three R\&D measures - the R\&D-to-sales ratios, the proportion of R\&D personnel to total employment, and the proportion of professional R\&D personnel to total employment - and three measures of human capital - the ratio of workers with post secondary education to total employment, the ratio of knowledge workers $^{18}$ to total employment, and the ratio of the number of employed scientists and engineers $^{19}$ to total employment. Industries were then assigned to a high-knowledge category if they fell in the top third on the basis of two of the R\&D indices and two of the human-capital indices.

In order to compare our firm-based classification scheme to the Lee and Haas measure, we assigned each of our industries to one of three categories - high, medium, and low. To do so, we used the Lee and Haas taxonomy to classify the industries included in our analysis. This yielded $x$ high-tech, $y$ medium-tech and $z$ low-tech industries. We then ranked our sample by our index and chose the first $x$ as high-tech, the second $y$ as medium-tech and the remaining $z$ as low-tech. Industries were assigned a value of 1, 2, or 3 , depending on the category they fell in. The correlation between the two classifications was only .38. The correlation is .46 for goods industries but only .18 for services industries. Once again, it is apparent that the firm-based classification yields a different view of how to divide industries into those that are more- and less-advanced.

\footnotetext{
${ }^{17}$ See Table 6.1 for details on related components.

${ }^{18}$ Occupations in the natural sciences, engineering and mathematics, in education, managers and administrators, social sciences, law and jurisprudence, medicine and health, and writing.

${ }^{19}$ Occupations in the natural sciences, engineering and mathematics.
} 
Despite the fact that we are interested in characterizing the spectrum of both goods and services industries, we also asked how our competency-based index compared to the OECD index that this organization applies just to manufacturing industries-noting that manufacturing industries are only a subsector of the goods-producing industries that we have been using. For this purpose, we use the ratio of R\&D to production (OECD, 1997) to rank our industries and divided them at the median into the high-value and low-value groups. The correlation between our high/low breakdown and the high/low breakdown derived from OECD-based $\mathrm{R} \& \mathrm{D}$ ratios is only .57. Once more, it is apparent that the firm-based classification system yields a different high/low dichotomy.

These differences suggest that there are a number of industries where small-firm profiles differ quite substantially from large-firm profiles. These differences are particularly noticeable for the services sector. If we are going to search for new, small, high-tech firms, we had best not focus our search solely on small firms in what are commonly perceived to be high-tech industries.

\section{Innovation, Skill Intensity, Technovation: Do They Have Separate Dimensions?}

In section 5, we demonstrated that a multidimensional index based on the innovation, technology use, and labour skill characteristics of new small firms yields a different set of high-tech industries than those based on aggregate industry measures. Given that, in our view, the former is superior on conceptual grounds, is it reasonable to infer that the rankings based on this multidimensional index constitute the definitive basis for classification? At first blush, one may suspect that this is indeed the case; other schemes-like the one advocated by the OECD_implicitly consider there to be only one ranking scheme that is important. What follows, however, suggests that any reliance on a single ranking may be ill-advised.

This section explores, in greater depth, the dimensionality of advanced competencies, and asks whether various combinations of advanced competencies will identify the same industries as high-tech leaders. In section 4, we demonstrated that each of advanced competencies-innovation, technology, and labour skill—do not necessarily yield identical industry rankings. Industries that fare well in one dimension (e.g., innovation) need not favour well in other dimensions (e.g., technology use). The various measures of innovation, labour skill, and technology were related, but imperfectly so. In this section, we explore the dimensionality of these differences, using principal component analysis. We include in the analysis the innovation, technology, and skill-based variables defined previously, as well as three new variables that capture the degree of innovation occurring in the industry. These are:

OBSPROD—the degree to which products become obsolete in an entrant's industry.

OBSPROC - the degree to which processes become obsolete in an entrant's industry. 
RTL—whether a firm reports investment spending on research and development, technology acquisition, and training.

The first two variables are derived from a question that asked firms to score, on a scale of 1 to 5 , the extent to which the forces that create obsolescence were important in their industry. For this paper, we classify a firm as finding these obsolescence conditions to be important if it scores a 4 or 5 on the question. The third variable is included to capture the extent to which a firm emphasizes all three of the dimensions-research and development, technology and human resources-that are used here to capture the advanced competencies of firms.

Principal component analysis will be used to summarize the extent to which the competencies that we have measured are different from one another-or the extent to which we can discover the number of independent dimensions that they measure. After the components are calculated, an industry score is obtained by averaging the principal component scores of all firms in an industry.

To reiterate the formula discussed previously, a principal component of the original variables $\mathrm{c}_{\mathrm{i}}$ is defined as:

$$
\mathrm{R}_{\mathrm{i}}=\mathrm{w}_{\mathrm{i} 1} * \mathrm{c}_{1}+\mathrm{w}_{\mathrm{i} 2} * \mathrm{c}_{2}+\ldots \ldots \ldots \ldots . . . \mathrm{w}_{\mathrm{in}} * \mathrm{c}_{\mathrm{n}}
$$

where $\mathrm{w}_{\mathrm{i}}$ are the weights and $\mathrm{c}_{\mathrm{i}}$ are the original variables. The relative size and sign of the weights define the nature of the competency that the principal component represents. Since the variables are positive and binary, the value of the component $R_{i}$ is positively related to the weights $\mathrm{w}_{\mathrm{i}}$ assigned to the different competencies $\mathrm{c}_{\mathrm{i}}$. For example, a high positive weight on the innovation variable, and on the human resource variables but a low weight on technology would represent those who innovate and stress human capital but whose focus on technology does not matter for this component.

Principal component analysis ${ }^{20}$ on the innovation, technological competency, and skill measures produces eight important principal components. ${ }^{21}$ The first (used previously in section 5) accounts for $26 \%$ of the total variation in the sample; the second, accounts for about $10 \%$, and the eight together account for $75 \%$ of the variance. The eigenvectors are presented in Table 6.1. The components are described in Table 6.2.

\footnotetext{
${ }^{20}$ Because each of the variables has the same scaling and for ease of interpretation, we have not standardized the variables when calculating the principal components.

${ }^{21}$ These components have eigenvalues that are greater than one.
} 
Table 6.1. Eigenvectors from the Principal Components Analysis

\begin{tabular}{|c|c|c|c|c|c|c|c|c|}
\hline & PRIN1 & PRIN2 & PRIN3 & PRIN4 & PRIN5 & PRIN6 & PRIN7 & PRIN8 \\
\hline INGEN & 0.24 & 0.36 & 0.21 & 0.06 & 0.22 & -0.12 & -0.04 & 0.05 \\
\hline INIMP1 & 0.12 & 0.15 & 0.04 & 0.09 & 0.02 & -0.05 & -0.06 & 0.04 \\
\hline INIMP2 & 0.19 & 0.28 & 0.17 & 0.04 & 0.20 & -0.02 & -0.01 & 0.09 \\
\hline INFREQ & 0.17 & -0.02 & -0.07 & 0.21 & 0.21 & 0.52 & -0.05 & 0.09 \\
\hline INIMP & 0.04 & 0.05 & 0.01 & 0.00 & 0.08 & 0.05 & 0.06 & 0.08 \\
\hline INTECH1 & 0.27 & 0.07 & -0.04 & 0.02 & -0.40 & -0.14 & -0.09 & 0.07 \\
\hline INRD & 0.16 & 0.03 & 0.02 & 0.21 & -0.08 & 0.06 & -0.02 & -0.02 \\
\hline OBSPROD & 0.22 & -0.43 & 0.52 & -0.03 & 0.06 & -0.08 & -0.05 & 0.05 \\
\hline INPROD & 0.20 & 0.27 & 0.11 & 0.13 & 0.19 & -0.00 & -0.06 & 0.09 \\
\hline INPROC & 0.19 & 0.29 & 0.15 & 0.00 & 0.09 & -0.13 & -0.05 & -0.03 \\
\hline INCOMP & 0.14 & 0.19 & 0.05 & 0.06 & 0.07 & -0.02 & -0.06 & 0.01 \\
\hline TEINP & 0.07 & -0.01 & 0.01 & -0.16 & -0.15 & 0.03 & 0.35 & 0.29 \\
\hline PROD1 & 0.22 & -0.11 & -0.13 & 0.23 & -0.12 & -0.06 & -0.41 & -0.54 \\
\hline LABTRAIN & 0.27 & 0.08 & 0.01 & -0.49 & -0.03 & 0.11 & 0.08 & -0.26 \\
\hline LABINT & 0.17 & 0.03 & -0.03 & -0.46 & -0.09 & 0.13 & 0.09 & -0.22 \\
\hline LABSKL & 0.23 & -0.21 & -0.43 & 0.04 & 0.28 & -0.25 & -0.08 & 0.22 \\
\hline LABFOR & 0.29 & 0.03 & -0.16 & -0.34 & 0.25 & 0.06 & 0.11 & -0.14 \\
\hline LABSCOR & 0.25 & -0.23 & -0.42 & 0.01 & 0.21 & -0.28 & 0.04 & 0.16 \\
\hline RTLINP & 0.07 & 0.07 & 0.02 & -0.02 & 0.03 & 0.03 & 0.04 & -0.04 \\
\hline
\end{tabular}


Table 6.2. A Description of the Principal Components

\begin{tabular}{|l|l|l|}
\hline Component & \multicolumn{1}{|c|}{ Positive Weights } & \multicolumn{1}{|c|}{ Negative Weights } \\
\hline PC1 & $\begin{array}{l}\text { Weights on all of Innovation, Technology and } \\
\text { Labour }\end{array}$ & \\
\hline PC2 & Innovation & $\begin{array}{l}\text { Obsolescence, Emphasis on Recruiting and } \\
\text { Training }\end{array}$ \\
\hline PC3 & Innovation and Obsolescence & Emphasis on Recruiting and Training \\
\hline PC4 & $\begin{array}{l}\text { Introduces New Products, R\&D, Computer } \\
\text { Processes and Information Technologies }\end{array}$ & Training Activities \\
\hline PC5 & $\begin{array}{l}\text { Innovation, Introduces New Products, } \\
\text { Emphasizes Recruiting Skilled Labour and } \\
\text { Performs Training }\end{array}$ & $\begin{array}{l}\text { Both New Technology and Adaption of } \\
\text { Technology, Technology Expenditures and } \\
\text { Computer Processes }\end{array}$ \\
\hline PC6 & $\begin{array}{l}\text { Traditional Innovator, and Frequent } \\
\text { Introduction of New Products }\end{array}$ & $\begin{array}{l}\text { Emphasizes Recruiting and Training Skilled } \\
\text { Labour }\end{array}$ \\
\hline PC7 & $\begin{array}{l}\text { High Technology Expenditures and } \\
\text { Emphasizes Information Technology in } \\
\text { Management }\end{array}$ & $\begin{array}{l}\text { Focus on Efficiency of Input Use and } \\
\text { Traditional Innovation Mode. }\end{array}$ \\
\hline PC8 & $\begin{array}{l}\text { Traditional Innovation, Adopts Technology, } \\
\text { and Recruits Skilled Labour }\end{array}$ & $\begin{array}{l}\text { Focuses on Efficiency of Input Use, Use of } \\
\text { Computer Processes and Trains Employees }\end{array}$ \\
\hline
\end{tabular}

The first component describes the general innovator-weighting as it does innovation (INGEN), important innovations (INIMP2), the two technology variables (INTECH1, INTECH2), and several training variables (LABFOR, LABSCOR, LABSKL). Other variables like research and development (INRD), computer technology (TECOMP), and uncertain industry conditions (OBSPROD, OBSPROC) also have relatively high positive weights.

The interpretation of the first principal component is relatively straightforward. Firms with a high score in this dimension will be generally doing more than one of these activities intensively. Since each of the original variables is a binary variable scaled from 0 to 1 , a firm must generally be engaged in the activities that receive the highest weights for it to receive a high score here.

The interpretation of the other components is less straightforward because each of the components has some variables with positive and others with negative weights. For example, the second component has relatively large positive weights on INGEN, INIMP2, INPROD, INPROC, and INCOMP. It has relatively large negative weights on OBSPROD, OBSPROC, LABSKL, and LABSCOR. Thus, this component captures firms that are innovators but do not face much obsolescence and do not value recruiting skilled labour or training, or the reverse. It should be noted that a firm can receive a high absolute score on this component score either by emphasizing innovation and not training, or by emphasizing training and not innovation.

The third component positively weights innovation (INGEN) that is novel (INIMP2) and has a great deal of product and process obsolescence (OBSPROD, OBSPROC ), but negatively weights recruiting and training (LABSKL, LABSCOR). This component then inversely weights important innovation and human resource strategies. 
The fourth component has positive weights on frequently introducing new products (INFREQ), emphasizing R\&D (INRD), computer-process technology (TECOMP), computers in management (TEINFO), and improving efficiency (PROD1). Negative weights are given to training activity variables (LABTRAIN, LABINT, LABFOR). This component inversely weights an emphasis on new products that is based on $R \& D$ expenditures and specific uses of computer technologies on the one hand and training activities on the other.

The fifth component positively weights innovation (INGEN), labour skills (LABSKL, LABSCOR), and training (LABFOR), but gives negative weights to technology variables involving the adoption of new technologies (INTECH1, INTECH2) and the use of computer processes (TECOMP). This component then is the innovator that emphasizes human capital but does not focus on technology.

The sixth component gives positive weights to traditional forms of innovation (INTRAD) and the frequent introduction of new products (INFREQ), but negative weights to recruiting (LABSKL) and training (LABSCOR). This represents the traditional innovator that does not emphasize human capital.

The seventh component gives a positive weight to high technology expenditures (TEINP) and the use of information technologies (TEINFO) but negative weights to traditional innovation (INTRAD) and production efficiencies (PROD1). This represents a technology firm that does not concern itself with the more traditional emphases that are found in small firms.

The eighth component positively weights traditional innovation (INTRAD), a high expenditure on technology acquisition (TEINP) and recruiting skill labour (LABSKL), but negatively weights an emphasis on efficiency (PROD1), computer processes (TECOMP) and training (LABTRAIN, LABINT). This represents the more traditional innovator that also emphasizes technology, but does not worry so much about traditional efficiency considerations in the production process.

These components provide a rich and varied picture of the innovation archetypes that can be found in the population. Three of these components are characterized by an emphasis on the narrow definition of innovation. The first component involves a comprehensive approach combining innovations, new technologies, and training. Firms in components two and five also stress innovation. In two instances, there is an emphasis on labour training skills in conjunction with innovation (components one and five). In one instance, there is an emphasis on R\&D spending and the introduction of frequent product changes (component four).

Two components (six and eight) both emphasize the traditional forms of quality and service competition. The latter combines this with a positive emphasis on training; the former with a negative emphasis. 
It should also be noted that there is an inverse emphasis in a number of cases with the stress given to either innovation and human resources (components two, three, and six). In these cases firms are either heavily emphasizing human resources but are not focusing on innovation, or firms are doing the reverse.

Three important observations emerge from this.

First, the emphasis on innovation is quite diverse-ranging from the momentous to the more incremental. Some entrants report that they are introducing product and process innovations. Others do not innovate in the narrow momentous sense, but they do emphasize the fact that they continuously introduce new products and that they perform R\&D. Still others focus on the traditional forms of competition that involve innovating with respect to quality, flexibility, and customization and also stress R\&D or a skilled labour force.

Second, R\&D is not restricted just to those reporting momentous innovations; it can also be found in those archetypes that emphasize a broader concept of innovation.

Third, an accent on labour skills is widespread. Four of the archetypes place a heavy emphasis on labour skills, some in conjunction with an emphasis on innovations per se, some with an emphasis on frequently introducing new products, some with an emphasis on more momentous innovation.

Up to this point, we have discussed how the dimensions revealed by the principal components differ. Each dimension has been examined separately, because they are constructed to be independent of one another. It is natural, however, to ask whether the separate dimensions, when considered as a whole, reveal which industries are more advanced. This is difficult to answer. By construction, the dimensions that are defined by each principal component are orthogonal to one another. Thus, the scores that are assigned to each industry by the principal components are not related to one another for the entire industry set. This means that any attempt to sum the scores across the components to produce an overall ranking is inherently superfluous. It provides little overall additional information. For example, the ranking obtained using the first principal component is identical to the ranking obtained using the sum of the first component and the other components. ${ }^{22}$

This independence necessarily exists only for the entire set of observations. It is still possible that the top industries are the same for each of the archetypes. To investigate this matter, the industries were ranked by each of the components. Each component was used to choose the top six goods industries and the top six services industries. Choosing the top six in the first component is straightforward because all weights are positive. They are simply the industries with the six highest scores. However, for the other components, the pattern that is identified by the component is simply the inverse weighting of separate factors, which can occur with one receiving a large positive emphasis and the other no

\footnotetext{
${ }^{22}$ It would also be the same if you compared the ranking of the second and the second plus all others. Of course, the ranking of the first and second are different.
} 
emphasis or the reverse. An industry can receive a large positive score on a particular component if its firms stress those strategies that have a positive weight in the component and they do not stress those with a negative weight, or they can receive a large negative score if its firms do not stress those with a positive weight and do stress those with a large negative weight. In each case, the industry fits the dimensions of the component since its stress on those variables that are positively and negatively weighted is negatively correlated. Because of this, we chose the industries with the three highest positive scores and the three largest negative scores for each component. Table 6.3 lists the goods industries that fall in the top six using each component- $\mathrm{a}+$ indicates that the industry is one of the top three with positive scores, a - indicates it is in the top 3 with regards to negative scores. Table 6.4 does the same for the top six services industries. In each table, the right-most column contains the sum of the number of times an industry falls into the topmost category.

Almost every industry falls into the topmost group using one of the principal components considered here. Twenty-three of the 25 goods industries are classified in the top six by one of the dimensions and are represented in Table 6.3; 19 of the 23 services industries are in Table 6.4. This is indicative of the universality of at least one dimension of advanced competencies. Not only are there differences in the types of competencies that are used at the industry level, but at least one aspect of these competencies is found in almost every industry.

It is also true that some industries appear more frequently in the topmost group. The most advanced industries have some overlap in their membership across the archetypes represented by each component. In the goods sector, the science-based electrical industry occurs in the top group three times. Printing and publishing occurs even more times. Similarly, in the services sector, several industries are repeatedly found to be at the top of the list. These are computer business services, farm services, recreation and other personal services.

While a small number of industries are found at the top using several different dimensions, this should not be interpreted to mean that there is a common ranking across all industries produced by the different components. There is not a large amount of overlap in the industries chosen by the various components. Advanced competencies are combined in different ways and almost every industry is found to stress at least one of the combinations. Moreover, different combinations of advanced competencies will yield different sets of high-tech leaders. 

Table 6.3. Ranking for Goods Industries Using Principal Components

\begin{tabular}{|c|c|c|c|c|c|c|c|c|c|}
\hline Industry & PC1 & PC2 & PC3 & PC4 & PC5 & PC6 & PC7 & PC8 & Sum \\
\hline Science-base electrical & + & + & & + & & & & & 3 \\
\hline Electrical-Product Differentiated & + & & & & & + & & + & 3 \\
\hline Printing and Publishing & + & - & + & & - & & + & + & 6 \\
\hline Food and Beverages & & & & + & & & & & 1 \\
\hline Plastic & + & & & & & & - & & 2 \\
\hline Rubber & & & & & & & + & & 1 \\
\hline Refined Petroleum and Chemical Products & + & & + & & + & & - & & 4 \\
\hline Crude Petroleum and Natural Gas & & & - & & & - & + & & 3 \\
\hline Farm Operations & & & + & + & & & & & 2 \\
\hline Machinery & & & & & + & - & & + & 3 \\
\hline Clothing & & & & & + & & & & 1 \\
\hline Primary Metal & + & & - & - & & + & & - & 5 \\
\hline Primary Logging and Mining & & & & & & - & & & 1 \\
\hline Miscellaneous-Non-scientific & & & & & & + & & & 1 \\
\hline Fabricated Metal-Miscellaneous & & + & & & & & & & 1 \\
\hline Fabricated Metal-Product Difference & & - & & & - & & & & 2 \\
\hline Furniture & & & - & - & & & & - & 3 \\
\hline Non-metallic & & + & & & & & & & 1 \\
\hline Wood-Miscellaneous & & - & & & & & & & 1 \\
\hline Construction Developers & & & & & & & - & & 1 \\
\hline Scale-based Wood & & & & - & & & & & 1 \\
\hline Motor Vehicles and Transportation & & & & & - & & & & 1 \\
\hline Construction-Heavy & & & & & & & & - & 1 \\
\hline
\end{tabular}


Table 6.4. Ranking for Services Industries Using Principal Components Analysis

\begin{tabular}{|c|c|c|c|c|c|c|c|c|c|}
\hline Industry & PC1 & PC2 & PC3 & PC4 & PC5 & PC6 & PC7 & PC8 & Sum \\
\hline Business Services-Personnel Agencies and Advertising Agencies & + & & & & & + & & & 2 \\
\hline Business Services-Architects, Engineers and Other Technical Services & + & & & & & & & & 1 \\
\hline Business Services-Computers and Related Services & + & & + & & + & & & & 3 \\
\hline Business Services-Other & & & + & - & & & & & 2 \\
\hline Business Services-Accounting, Lawyers, and Management Consultants & & & & - & - & & & & 2 \\
\hline Real Estate-Agents & & & - & & & & + & & 2 \\
\hline Farm Services & & & & + & - & - & + & + & 5 \\
\hline Services for Forestry, Petroleum, and Natural Gas & & & & + & & & & - & 2 \\
\hline Services-Food and Beverages & & & & & + & + & & & 2 \\
\hline Services-Accommodation & & - & - & & & & & & 2 \\
\hline Services-Other & & - & & & & & + & + & 3 \\
\hline Services-Personal & & + & & + & - & - & - & - & 6 \\
\hline Services-Amusement and Recreation & + & + & - & & & & - & & 4 \\
\hline Retail-Food & & & & & & - & & & 1 \\
\hline Retail-Motor Vehicles & + & - & & & & & & & 2 \\
\hline Retail-Other & & & + & & + & & & + & 3 \\
\hline Transportation and Storage & & & & & & & - & & 1 \\
\hline Wholesale-electric, Machinery, Metal and Motor Vehicles & & & & - & & & - & & 2 \\
\hline Construction Services & & + & & & & & & - & 2 \\
\hline
\end{tabular}




\section{Conclusion}

Evidence of the importance of science and technology is provided by the ubiquitous effect of the microchip. The introduction of the electronic microchip has heralded a major change in the way that business is being conducted. New machines that have embedded in them the capabilities of the microchip_-such as computer numerically controlled machines, flexible manufacturing sectors, or robots - are penetrating the manufacturing process. In the services sector, computers have allowed airlines to more closely tailor demand to supply. In the financial sector, they have facilitated the automation of manual transactions.

Applications involving the microchip are not the only highly visible manifestations of advanced technology that are transforming various production processes. Biotechnology is affecting the pharmaceutical industry. New composite materials are being incorporated into many durable manufacturing sectors.

The effects of the new industrial revolution are easily seen in some areas-for example, in the growth of certain high-profile new firms related to computer or software production. But these industries are not the only ones that should be classified as being advanced. This paper has argued that simply citing such industries as being the only more-advanced industries is acceptable neither on a priori nor on empirical grounds.

The evolution of new technologies has led to attempts to measure the extent to which different sectors are benefiting from the application of these technologies. Some of this interest stems from a simple wish to understand how technology diffuses across sectors, or to understand how the spread of new technology affects a country's comparative advantage and trading patterns. These are legitimate intellectual exercises that are aimed at improving our understanding of how the economic system operates. Other attempts at classification that serve to stigmatize firms in certain sectors as backward are less meritorious. These latter attempts, since they are so obviously emotive, need to be carefully investigated before they are accepted. One of the objectives of this paper was to ask whether existing classification schemes are adequate for deciding whether new highknowledge firms are concentrated only in some sectors.

To do so, we examined several existing taxonomies with an eye to using them to classify industries as either high- or low-tech. We argued that several existing attempts to systematically define which industries are more advanced suffer from several serious deficiencies. First, they have tended to use partial measures. The OECD's practice (1994, 1997) of focusing essentially on R\&D intensity is one such example. Second, they have treated advanced capabilities as being unidimensional-that is, of being capable of representation by one summary statistic. Finally, most attempts ignore the fact that industries are not homogeneous and that focusing on measures that are derived essentially from large-firm characteristics may not accurately portray the small-firm segment that plays such a critical role in introducing new technologies. 
Providing a taxonomy that allows the entire spectrum of industries to be classified based on their innovation skills requires the collection of comprehensive data on where innovation is occurring and new technologies are being applied. This paper has employed data from a recent Statistics Canada survey to do so. It develops various new measures that can be used to study the extent to which sectors find themselves with a preponderance of new technology-based firms. In doing so, it addresses the problems that are associated with using an existing set of measures. The paper focuses directly on the advanced competencies of firms and develops a rich and varied set of measures based directly on firms' own evaluations of their competencies in three crucial areas. This provides a multidimensional view of the advanced competencies of firms-by examining innovation, skill development, and technological capabilities. Within each of these categories, several variables are used to capture aspects that are potentially different.

The new firms that we identify as advanced in this study have the characteristics associated with new technology-based firms. They are innovative; they introduce new products and processes; they place great emphasis on technology; they appreciate the importance of a skilled workforce, and they train their workers.

We examine how our competency-based measure of technological-prowess that is derived from the characteristics of entrants compares with alternate measures based on incumbent firms. Our competency-based measure does not divide the population into high- and low-tech groups in the same way that alternate approaches that use industry aggregates do. Either these previous approaches rely on too few variables or, by focusing on industry aggregates, they ignore the heterogeneous nature of industries and fail to capture the unique character of new, small firms.

There are some similarities between the rankings developed here and those developed previously that take more aggregate partial approaches. Both find that computer-related business services and electronic products are at the top of the list of industries in terms of the percentages of firms with advanced capabilities. But the new advanced competencybased index derived here that comes from new firms pinpoints other industries that are not normally included in the top group - recreational services, printing and publishing, and farm services. These are industries where a focus on innovative skills or processes is important. But they are not the type of industries that normally garner headlines.

The paper also shows that there is more than one dimension to advanced knowledge. While there are strong connections between the innovation and the skill-based index derived from the competency of new firms, the relationship between these advanced competencies and the technological variables is lower, thereby indicating that the latter contains some dimensions that are different from the others.

A closer examination of the relationship between the detailed underlying variables points to other differences. Product and process innovation tends to be done by different firms. An emphasis on advanced technology is pursued by a different group than that which focuses on R\&D and product innovation. Firms combine competencies in different ways. Some firms combine an emphasis on labour skills with R\&D spending, others with 
technology. Perhaps what is most significant is that most industries stress at least one of these combinations. In the end, most industries can be said to be advanced in one or other of the dimensions of innovativeness, worker skills, or technology use. When it is recognized that knowledge-based firms can encompass any combination of these skills, then most industries can be described as ranking high in some knowledge trait. This suggests the use of any single index (including the one devised here for the purpose of comparison to existing indices) does an injustice to the degree of diversity and technological competence in the underlying population of new firms.

These findings are relevant to the debate on the importance of high-knowledge, high-tech firms. The data that have been adduced herein suggest that these firms are ubiquitous. This is not to deny that some sectors are more visible. But industries that might be classified as low-tech on the basis of indices are not devoid of high-tech firms-on average, they contain half as many high-tech firms as can be found in high-tech industries. It should not be claimed that high-knowledge, high-tech firms are confined exclusively to these more visible industries. 


\begin{tabular}{|c|c|c|}
\hline Class & Industry & Sic Codes \\
\hline Goods & Clothing & $17,18,19,24$ \\
\hline Goods & Food and Beverages & 10,11 \\
\hline Goods & Furniture & 26 \\
\hline Goods & Plastic & 16 \\
\hline Goods & Wood & 25 with exception of 251 \\
\hline Goods & Science-based Electrical & 334335336 \\
\hline Goods & Scale-based Wood & 251 \\
\hline Goods & Fabricated Metal & $\begin{array}{r}305 \text { and all other } 301-309 \text { with } \\
\text { exception of } 301 \text { and } 306-8\end{array}$ \\
\hline Goods & Non-metallic & 35 \\
\hline Goods & Paper & 27 \\
\hline Goods & Primary Metal & 29 \\
\hline Goods & Printing and Publishing & 28 \\
\hline Goods & Rubber & 15 \\
\hline Goods & Miscellaneous-Non-Scientific & 39 with exception of 391 \\
\hline Goods & Electrical_Product-Differentiated & 331332333336338339330 \\
\hline Goods & Fabricated Metal & 306307308 \\
\hline Goods & Machinery & 31 \\
\hline Goods & Motor Vehicles and Transportation & 32 \\
\hline Services & Business Services_-Personnel and Advertising Agencies & 771774 \\
\hline Services & Business Services-Architects, Engineers and Technical Services & 775 \\
\hline Services & Business Services-Computers and Related Services & 772 \\
\hline Services & Business Services-Other & 779 \\
\hline Services & Business Services-Accounting, Lawyers, Management Consultants & 773776777 \\
\hline Goods & Construction-Developers & 40 \\
\hline Goods & Construction-General Contracting & 42 \\
\hline Goods & Construction-Heavy & 41 \\
\hline Services & Construction-Services & 44 \\
\hline Services & Real Estate-Agents & 76 \\
\hline Services & Real Estate-Operators & 75 \\
\hline Goods & Farm Operations & 1 \\
\hline Services & Farm Services & 23 \\
\hline Services & Communications and Utilities & 4849 \\
\hline Goods & Crude Petroleum and Natural Gas & 7 \\
\hline Goods & Primary Products—Mining, Logging, Quarries and Sand Pits & 468 \\
\hline Services & Services for Forestry, Petroleum and Natural Gas & 59 \\
\hline Services & Services_Food and Beverages & 92 \\
\hline Services & Services-Accommodation & 91 \\
\hline Services & Services-Other & 99 \\
\hline Services & Services-Personal & 97 \\
\hline Services & Services-Amusement and Recreation & 96 \\
\hline Goods & Refined Petroleum and Chemical Products & 3637 \\
\hline Services & Retail-Food & 60 \\
\hline Services & Retail-Motor Vehicles & 63 \\
\hline Services & Retail Other & 6162646569 \\
\hline Services & Finance, Insurance, and Other Financial Intermediaries & 7071727374 \\
\hline Services & Transportation and Storage & 4547 \\
\hline Services & Wholesale-General & 5051525359 \\
\hline Services & Wholesale Electric, Machinery, Metal, and Motor Vehicles & 54555657 \\
\hline
\end{tabular}




\section{References}

Abernathy, W.J. and J.M. Utterbach. 1978. "Patterns of Industrial Innovation". Technology Review 80: 41-7.

Acs, Z.S and D.B. Audretsch. 1990. Innovation and Small Firms. Cambridge, Mass: MIT Press.

Äkerblom, M., M. Virtaharju and A. Leppälahti. 1996. "A Comparison of R\&D Surveys, Innovation Surveys and Patent Statistics Based on Finnish Data". Innovation, Patents and Technological Strategies. Paris: OECD.

Audretsch, D.B. 1995. Innovation and Industry Evolution. Cambridge, Mass: MIT Press.

Australian Bureau of Statistics. 1989. Manufacturing Technology Statistics. Cat. No. 81230. Canberra.

Baldwin, J.R. 1995. The Dynamics of Industrial Competition: A North American Perspective. Cambridge: Cambridge University Press.

Baldwin, J.R. 1997a. Innovation and Intellectual Property. Catalogue No. 88-515E. Ottawa: Statistics Canada.

Baldwin, J.R. 1997b. The Importance of $R \& D$ for Innovation in Small and Large Canadian Manufacturing Firms. Research Paper No. 107. Analytical Studies Branch. Ottawa: Statistics Canada.

Baldwin, J.R. 1998. A Portrait of Entry and Exit. Research Paper No. 121. Analytical Studies Branch. Ottawa: Statistics Canada. Forthcoming.

Baldwin, J.R., W. Chandler, C. Le and T. Papailiadis. 1994. Strategies for Success: A Profile of Growing Small and Medium-Sized Enterprises (GSMEs) in Canada. Catalogue No. 61-523ER. Ottawa: Statistics Canada.

Baldwin, J.R., B. Diverty and D. Sabourin. 1995. "Technology Use and Industrial Transformation: Empirical Perspectives." In Technology, Information and Public Policy. Edited by T. Courchene, John Deutsch Institute for the Study of Economic Policy. Kingston, Ontario: Queen's University: 95-130.

Baldwin, J.R. and Moreno Da Pont. 1996. Innovation in Canadian Manufacturing Enterprises. Catalogue No. 88-513. Ottawa: Statistics Canada.

Baldwin, J.R. and P.K. Gorecki. 1993. "Dimensions of Labor-Market Change in Canada: Intersectoral Shifts, Job and Worker Turnover." Journal of Income Distribution 3: 14880 . 
Baldwin, J.R., T. Gray and J. Johnson. 1997. "Advanced Technology Use and Training in Canadian Manufacturing." Canadian Business Economics, 4: 51-70.

Baldwin, J.R. and J. Johnson. 1996. "Human Capital Development and Innovation: A Sectoral Analysis." The Implications of Knowledge-Based Growth for Micro-Economic Policies, edited by P. Howitt, 83-110. Calgary: Calgary University Press.

Baldwin, J.R. and J. Johnson. 1998. "Innovator Typologies, Related Competencies, and Performance." In Microfoundations of Economic Growth: A Schumpeterian Perspective, edited by C. Green and C. McCann, Ann Arbour: University of Michigan Press.

Baldwin, J.R. and M. Rafiquzzaman. 1994. Structural Change in the Canadian Manufacturing Sector (1970-90). Research Paper No. 61. Analytical Studies Branch. Ottawa: Statistics Canada.

Baldwin, J.R and M. Rafiquzzaman. 1998. "The Effect of Technology and Trade on Wage Differentials Between Nonproduction and Production Workers in Canadian Manufacturing." In Innovation, Industry Evolution and Employment, edited by D.B. Audretsch and R. Thurik, Cambridge: Cambridge University Press. Forthcoming.

Baldwin, J.R. and D. Sabourin. 1995. Technology Adoption in Canadian Manufacturing Enterprises. Catalogue No. 88-512. Ottawa: Statististics Canada.

Baldwin, J.R., D. Sabourin and P. Hanel. 1998. The Determinants of Innovation in Canadian Manufacturing Industries. Research Paper No. 122. Analytical Studies Branch. Ottawa: Statistics Canada. Forthcoming.

Baldwin, J.R., D. Sabourin and M. Rafiquzzaman. 1996. Benefits and Problems Associated with Technology Adoption in Canadian Manufacturing. Catalogue No. 88514E. Ottawa: Statistics Canada.

Bartel, A.P. and F.R. Lichtenberg. 1987. "The Comparative Advantage of Educated Workers in Implementing New Technology." Review of Economics and Statistics 69: 111.

Berman, E, J. Bound and Z. Griliches. 1994. "Changes in the Demand for Skilled Labour within U.S. Manufacturing Industries.” Quarterly Journal of Economics. 109: 367-98.

Bound, E.J. and G. Johnson. 1992. "Changes in the Structure of Wages in the 1980s: an evaluation of alternative explanations." American Economic Review 82: 371-92.

Cohen, W.M. and R.C. Levin. 1989. "Empirical Studies of Innovation and Market Structure," In Handbook of Industrial Organization, Vol. II, edited by R. Schmalensee and R.D. Willig, pp. 1059-1110. Amsterdam: North-Holland. 
Cooper, A.C., G.E. Willard and C.Y. Woo. 1986. "Strategies of high-performing new and small firms: a reexamination of the niche concept." Journal of Business Venturing 1: 24760 .

David, P. 1990. "The Dynamo and the Computer." American Economic Review, Papers and Proceedings 80(2): 355-61.

Davis, S. and J. Haltiwanger. 1992. "Gross Job Creation, Gross Job Destruction, and Employment Reallocation.” Quarterly Journal of Economics 107: 819-64.

Doms, M., T. Dunne and K. Troske. 1997. "Workers, Wages and Technology." Quarterly Journal of Economics 112:253-290.:

Fleissner, P., W. Hofkirchner and M. Pohl. 1993. "The Austrian Experience with Literature-based Innovation Output Indicators." In New Concepts in Innovation Output Measurement, edited by A.H. Kleinknecht and D. Bain, pp. 85-112. London: Macmillan.

Gort, M and S. Klepper. 1982. "Time Paths in the Diffusion of Product Innovations." Economic Journal 92: 630-53.

Hollander, S. 1965. The Sources of Increased Efficiency: A Study of Dupont Rayon Plants. Cambridge, Mass.: MIT Press.

Kleinknecht, A., P.T. Poot. and J.O.N. Reijnen. 1991. "Formal and Informal R\&D and Firm Size: Survey Results from the Netherlands." In Innovation and Technological Change, edited by Zoltan J. Acs and David B. Audretsch, New York: Harvester/Wheatsheaf.

Kleinknecht, A.H. and D. Bain (eds). 1993. New Concepts in Innovation Output Measurement. London: Macmillan.

Kleinknecht, A.H, J.O.N. Reijnen and W. Smits. 1993. "Collecting Literature-based Innovation Output Indicators. The Experience in the Netherlands." In New Concepts in Innovation Output Measurement, edited by A.H. Kleinknecht and H., D. Bain, pp. 42-84. London: Macmillan.

Klepper, S. 1996. "Entry, Exit, Growth and Innovation over the Product Life Cycle." American Economic Review 86: 562-83.

Klepper, S. and J.H. Millar. 1995. "Entry, Exit and Shakeouts in the Unites States in New Manufactured Products." International Journal of Industrial Organization 13(4): 5678-91.

Lee, F.C. and H. Haas. 1996. "A Quantitative Assessment of High-Knowledge Industries Versus Low-Knowledge Industries." In The Implications of Knowledge-Based Growth for Micro-Economic Policies, edited by P. Howitt. Calgary: Calgary University Press. 
Mowery, D.C. and N. Rosenberg. 1989. Technology and the Pursuit of Economic Growth. Cambridge: Cambridge University Press.

Organization for Economic Cooperation and Development. 1994. Science and Technology Policy. Review and Outlook. Paris.

Organization for Economic Cooperation and Development. 1996a. Science, Technology and Industry Outlook. Paris.

Organization for Economic Cooperation and Development. 1996b. Technology, Productivity and Job Creation. Vol. 2. Analytical Report. Paris.

Organization for Economic Cooperation and Development. 1997. Science, Technology and Industry. Scoreboard of Indicators. Paris.

Picot, G., J.R. Baldwin and R. Dupuy. 1994. Have Small Firms Created a Disproportionate Share of New Jobs in Canada? A Reassessment of the Facts. Research Paper No. 71. Analytical Studies Branch. Ottawa: Statistics Canada.

Robson, M., J. Townsend and K. Pavitt. 1988. "Sectoral Patterns of Production and Use of Innovations in the UK: 1945-83." Research Policy 7 (1): 1-14.

Rothwell, R. and W. Zegveld. 1982. Innovation and the Small and Medium-Sized Firm. London: Francis Pinter.

Scherer, F.M. 1982. "Interindustry technology flows in the United States." Research Policy 11:227-46.

Schmookler, J. 1959. "Bigness, Fewness and Research." Journal of Political Economy 67: 628-32.

Shimsoni, D. 1970. “The Mobile Scientist in the American Instrument Industry.” Minerva 3

U.S. Bureau of the Census. 1989. Manufacturing Technology: 1988. SMT(88)-1. Washington, D.C. 